Portland State University

PDXScholar

Fall 2021

\title{
Project to Establish Growth \& Mortality Rates of Three Carex Species in Two Planting Types at Thomas Dairy Site, Tigard, Oregon
}

Ben Huffine

Portland State University

Follow this and additional works at: https://pdxscholar.library.pdx.edu/mem_gradprojects

Part of the Environmental Health and Protection Commons, Environmental Indicators and Impact Assessment Commons, and the Natural Resources Management and Policy Commons Let us know how access to this document benefits you.

\section{Recommended Citation}

Huffine, Ben, "Project to Establish Growth \& Mortality Rates of Three Carex Species in Two Planting Types at Thomas Dairy Site, Tigard, Oregon" (2021). Environmental Science and Management Professional Master's Project Reports. 73.

https://pdxscholar.library.pdx.edu/mem_gradprojects/73

https://doi.org/10.15760/mem.76

This Project is brought to you for free and open access. It has been accepted for inclusion in Environmental Science and Management Professional Master's Project Reports by an authorized administrator of PDXScholar. Please contact us if we can make this document more accessible: pdxscholar@pdx.edu. 


\section{Project to Establish \\ Growth \& Mortality Rates of Three Carex Species in Two Planting Types at Thomas Dairy Site, Tigard, Oregon}

Ben Huffine

12/08/2021

Portland State University

ESM Department

Master of Environmental Management Project Report 


\begin{abstract}
Clean Water Services (CWS) currently increases the diversity of their wetland restoration projects using a plug planting method utilizing juvenile herbaceous plants. They have planted most of their projects using this method and plan to continue until a better one is discovered. According to the literature reviewed in this paper, juvenile plants are smaller and weaker than more mature plants and therefore have higher mortality rates. This paper is the culmination of work completed of phase 1 of this two-phase project. The objective of this project (both phases) was to design and establish a study that would test, in the field, two common wetland planting methods: installation of plugs of juvenile plants at a relatively high density and installation of containerized, more mature plants at a lower density. This study will examine three species of Carex frequently used in wetland restoration (Carex stipata, C. obnupta, and C. unilateralis) and compare the growth and mortality of mature versus juveniles of these species within Thomas Dairy Site in the Tualatin River Watershed. For phase 2, at Thomas Dairy Site, 13 randomly selected plots will each containing six subplots including a subplot planted with monocultures of each of the three plants, and two sizes (i.e., mature $C$. stipata, juvenile $C$. stipata, mature $C$. obnupta, juvenile $C$. obnupta, mature $C$. unilateralis, and juvenile $C$. unilateralis). These will be monitored for five years, during which mortality rates will be recorded once a year and total percent cover recorded three times a year. I hypothesize that the mature plants will have a higher percent cover after five years because juvenile plants are more susceptible to die over that timeframe and may have slower growth rates overall. Answering these questions will allow CWS and other wetland restoration managers to achieve greater plant coverage, reduce waste, and reduce costs.
\end{abstract}




\section{Acknowledgments}

John Goetz III: Without you, this project would not have been possible. This was your idea, and your excitement carried me through the many months attempting to get this started. I greatly appreciate all the information and guidance you offered me.

Dr. Joseph Maser: Thank you so much for all the meetings, and edits you made on my project. Without your help this project would not be heading in the direction it is now.

Endre Elteto, Jared Kinnear, Randy Lawrence: All three of you offered your expertise without a second thought and because of you, we now have a mathematical foundation to this project.

Aubrey Harris: Even though we did it during the heat wave, you made it possible for us to collect soil samples. Thank you so much. Also, thank you for all the extra water you gave me.

Dr. Yangdong Pan: Without you I would have been lost when it came to figuring out how many plots we needed. Thank you.

Brian Shepard, Robin Baker, Benjamin Protzman, Krishna Sunglieng: Thank you all for your help on the drone flights, deciding plot and soil locations, and the additional support you offered in forming the project plan.

Dr. Catherine de Rivera: Thank you for serving on my committee and being willing to offer time and work in your busy schedule.

Cheyenne Canfield: Thank you for being the absolute biggest support in my life and supporting me through this project and graduate school. Also, thank you for being the first to see and edit my. .. rough paper. 


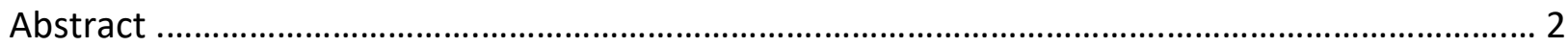

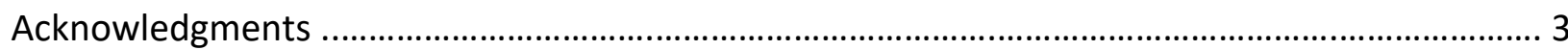

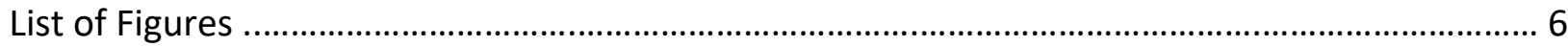

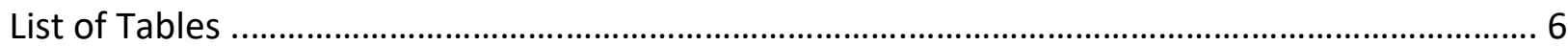

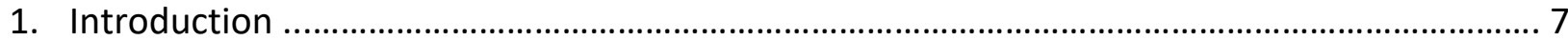

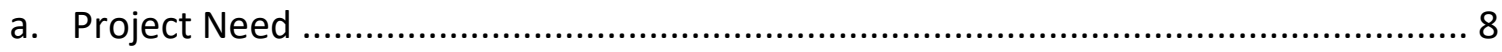

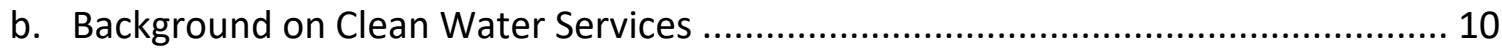

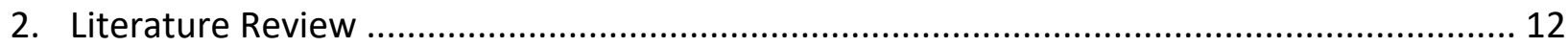

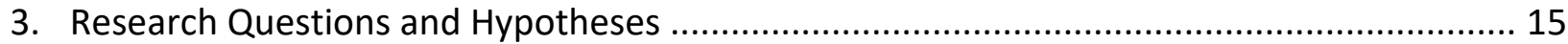

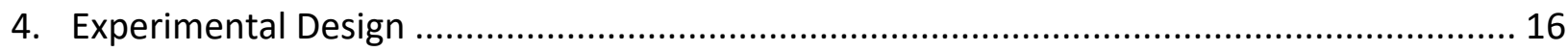

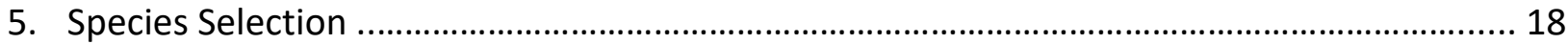

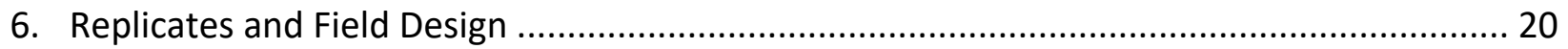

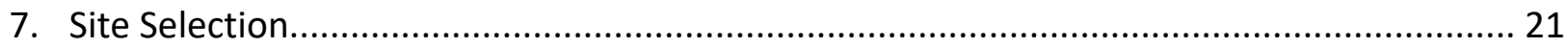

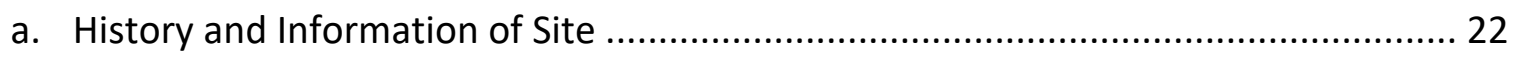

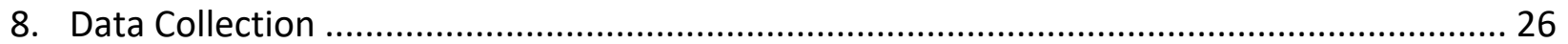

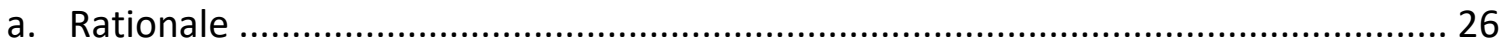

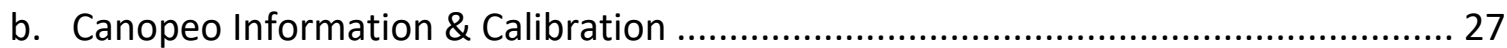

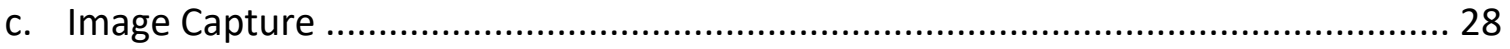

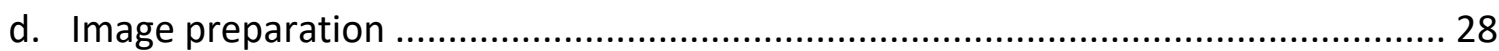

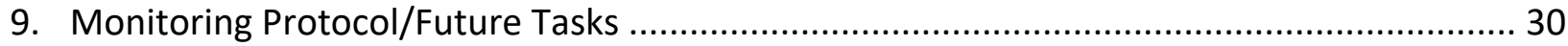

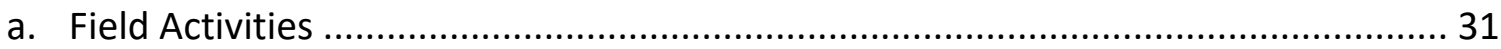

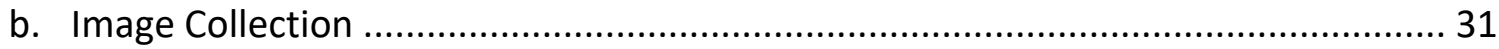

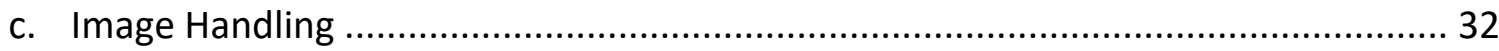

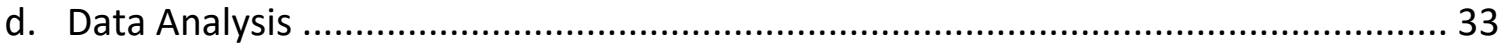

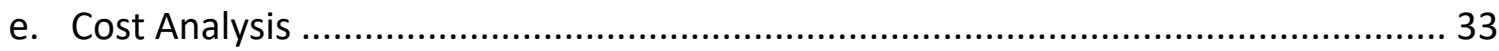

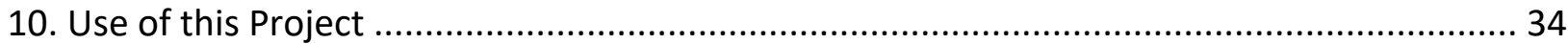

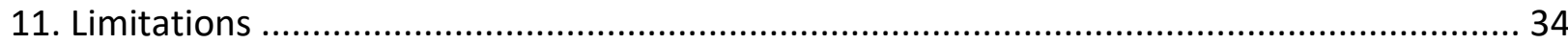




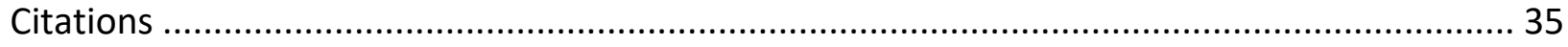

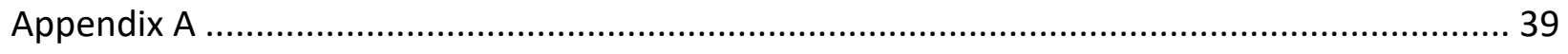

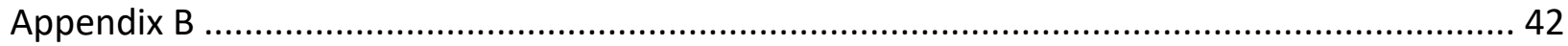

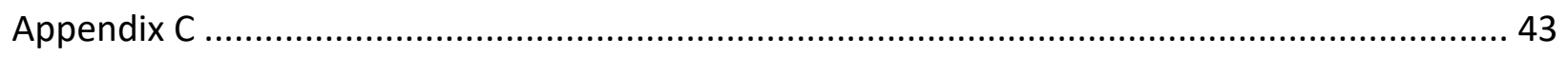




\section{List of Figures}

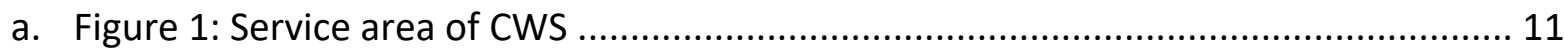

b. Figure 2: Map of area the Thomas Dairy Site is situated in with specific area outline in

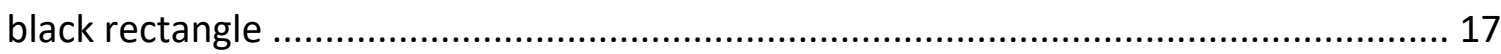

a. Figure 3: Map of plot locations in Thomas Dairy Site ........................................ 18

b. Figure 4: Model of subplot orientation within plots ............................................. 18

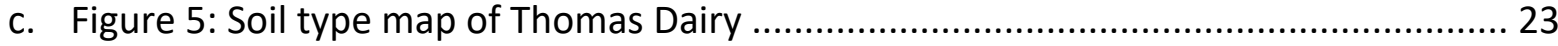

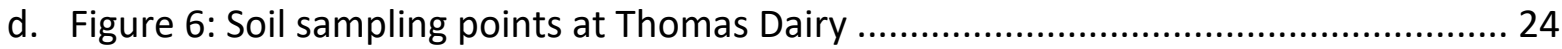

e. Figure 7: Carex obnupta image captured at $25^{\prime}$ with a 10 x 10 grid ........................... 28

f. Figure 8: C. obnupta image after living matter not of species is removed ................... 30

g. Figure 9: Image of Fig 8 after being run through Canopeo software .......................... 30

\section{List of Tables}

a. Table 1: Notable findings from soil sample analysis from Thomas Dairy 


\section{Introduction}

Clean Water Services (CWS) aims to protect public health while enhancing the Tualatin River Watershed. Through combining science and nature CWS works in partnership with others to safeguard the river's health and vitality for the more than 600,000 residents and the many businesses in Washington County, Oregon.

As part of meeting their water quality permit requirements, CWS provides natural resources management and stewardship thought the implementation of stream and wetland restoration projects. As part of the portfolio of restoration projects CWS increases the plant community diversity on a vast majority of their wetland restoration sites with herbaceous plant plugs. While this method is labor-efficient, it tends to result in high amounts of mortality, and thus the unsuccessful establishment of these species, according to local Tualatin River Watershed restoration experts (Elteto et al., 2021). A possible solution to this is to switch to larger (containerized) plants of the same species, instead of continuing to use the plug method. The purpose of this project is to test if planting restoration wetlands with larger, more mature (containerized) Carex species is more successful than the current method of planting with smaller, juvenile plants (plugs). Based on the literature reviewed for this project, we believe that the larger plants will have less mortality and greater overall growth after five years of observation, as they are less likely to die and are more resilient to environmental disturbances.

By the end of this project, we hope to have clear data that either shows that the current method of planting (plugs) is as effective or more effective than planting with containerized plants, or the data will show that using larger plants is more effective than the current method (plugs). A finding that planting larger plants is more effective would support a shift in planting methods by CWS. My hope is that CWS will share the findings with others in the wetland restoration field and encourage others to switch methods if relevant. If the data suggest that the current method is best, we expect no changes in plant size will occur.

This project, which is a coordinated effort between CWS and myself, is in two phases. The first phase includes everything included in this paper: the literature review, formation of the research questions and hypotheses, and development of the experimental design. The 
second phase, which I will not be involved in, but will be guided by this document will include the field work, the data analysis, and the final report. For my Master of Environmental Management (MEM) project, and final paper, I have carried out and completed phase one of this project. Beyond phase one, the project will continue for just over five additional years (five years of monitoring, plus the time needed for data analysis and final report). In addition to the necessary parts of phase one, I have also included some background information on the site, and community partner (CWS).

\section{Project Need}

CWS spends hundreds of thousands of dollars every year on restoring wetlands within the Tualatin River Watershed. The main guiding document for all CWS's restoration efforts since 2005 is the Healthy Streams Plan (Smith \& Ory, 2005). The goal of the plan is "to utilize scientific knowledge and innovation to improve watershed and stream health for community benefit". The plan discusses and guides what CWS does to protect and restore wetlands within the Tualatin River Watershed to encourage and promote stream health, as the quantity and quality of wetlands in the watershed impact the health of the streams (Gilliam, 1994). Additionally, the work that CWS is conducting to restore and protect wetlands is highly valued by the community. According to a 2002 public survey of CWS stakeholders, $97 \%$ of participants stated that the protection of wetlands was an important value to them (Davis, Hibbitts \& McCaig, 2002).

A substantial part of the restoration work CWS completes is in the replanting of degraded wetlands (Clean Water Services, 2021). The wetlands managed and cared for by CWS are replanted with a wide range of woody and herbaceous plants, and each site has its own special collection of different species and plant types. Along with planting herbaceous species, CWS utilizes a range of other restoration techniques that primarily focus on the revegetation of wetlands.

According to John Goetz III, who is the project manager on many wetland restoration projects, CWS replants wetlands with herbaceous plants by use of plug planting, where the 
plants are quickly stuck into holes an equal distance apart (usually around 30 centimeters). While this method is labor efficient, the plants tend to be in the immature and juvenile stages, usually less than a year old, if not younger. Through visual observations by both contractors and project managers, this method appears to result in a high number of mortalities within herbaceous species. These observations and a proposed solution form the foundation of this project.

The proposed solution is that CWS should start using more mature herbaceous plants to replant the wetlands instead of the immature plants, when applicable. These mature plants come from nurseries in one-gallon containers, while plugs come in trays usually containing a dozen juvenile plants. The hope is that this new method will reduce mortality rates to the point that the much lower density is more than made up for with higher survival yielding an increase in ground cover percentages. Currently it is estimated that the range of mortality is usually around $30-40 \%$ for plugs, compared to $10 \%$ for containerized plants (Elteto at al., 2021). It is possible that using containerized plants, will save CWS time, money, and result in increased diversity and resiliency of restoration projects. Additionally, using containerized plants will reduce waste as containers are often reusable, while the plug containers are a one-time use plastic product that are neither reusable nor recyclable. The information gathered from this study can be shared with other restoration managers and, if mature plants improve outcomes, influence how wetland restoration sites are planted. This study can additionally encourage research into how mature versus immature plants function within ecosystems, as the literature on this topic is sparce. It is also known that these Carex plants spread through shoots and runners, meaning that new plants are at a disadvantage (Pauliukonis \& Gough, 2004). Additionally, this study will provide insights into the growth habits and success of the specific species selected and will open the door to the exploration of species-specific planting methods to maximize plant material utilization and enhance restoration project outcomes.

Only two papers found from a comprehensive search in JSTOR and Google Scholar discussed plants with relationships between size and mortality (Cook, 1979; Zotz et al., 2001), and only one paper found discussed percent cover of plants within wetlands and how that relates to mortality (Clark \& Wilson, 2001). It is possible that there are additional papers, but 
they could not be found. Searching the names of the species and other keywords such as "mortality, percent cover, age, size" yielded very few results. It was not until I broadened the search to "plants" instead of the Carex species that I was able to find the few papers discussed in the literature review. As these three papers suggest, larger and more mature plants have higher survival rates than young, small plants. This lack of scientific literature can be attributed to the idea that planting larger, older plants and expecting them to survive at higher rates is "common sense" among the practitioners that restore wetlands. Moreover, it is conceivable that those who have or have not found this to be true in their experience are more hands-on in the field and are less inclined to take the time or effort to create a report or try and publish a paper on this topic. With strong science and statistical analysis, this project can advance wetland restoration success and contribute to the literature on this topic.

\section{Background on Clean Water Services}

Clean Water Services, founded in 1970, provides wastewater services to residents within the Tualatin River Watershed, which includes parts of Portland, Beaverton, Tigard, Tualatin, Hillsboro, Forest Grove, and Gaston (Figure 1). As is outlined in the Healthy Streams Plan (2005), CWS has launched or maintained restoration projects along more than 160 stream miles within the Tualatin River Watershed and collaborations with more than 40 community partners have resulted in the installation of more than 12 million plants. Most of their restoration efforts are focused on hydrological systems, encompassing creeks, streams, rivers, lakes, ponds, and wetlands. Because wetlands are a critical part of the greater hydrologic cycle (Bullock \& Acreman, 2003), CWS has concentrated many of its efforts on the restoration of degraded wetlands. 
CWS is involved in multiple restorative actions, such as planting trees along stream banks to shade the waterbody and reduce water temperatures, and creating constructed wetlands like the Fernhill wetland that, "creates an ecological bridge between the treatment facility and the watershed, where water is cleansed further, cooled and naturalized before its

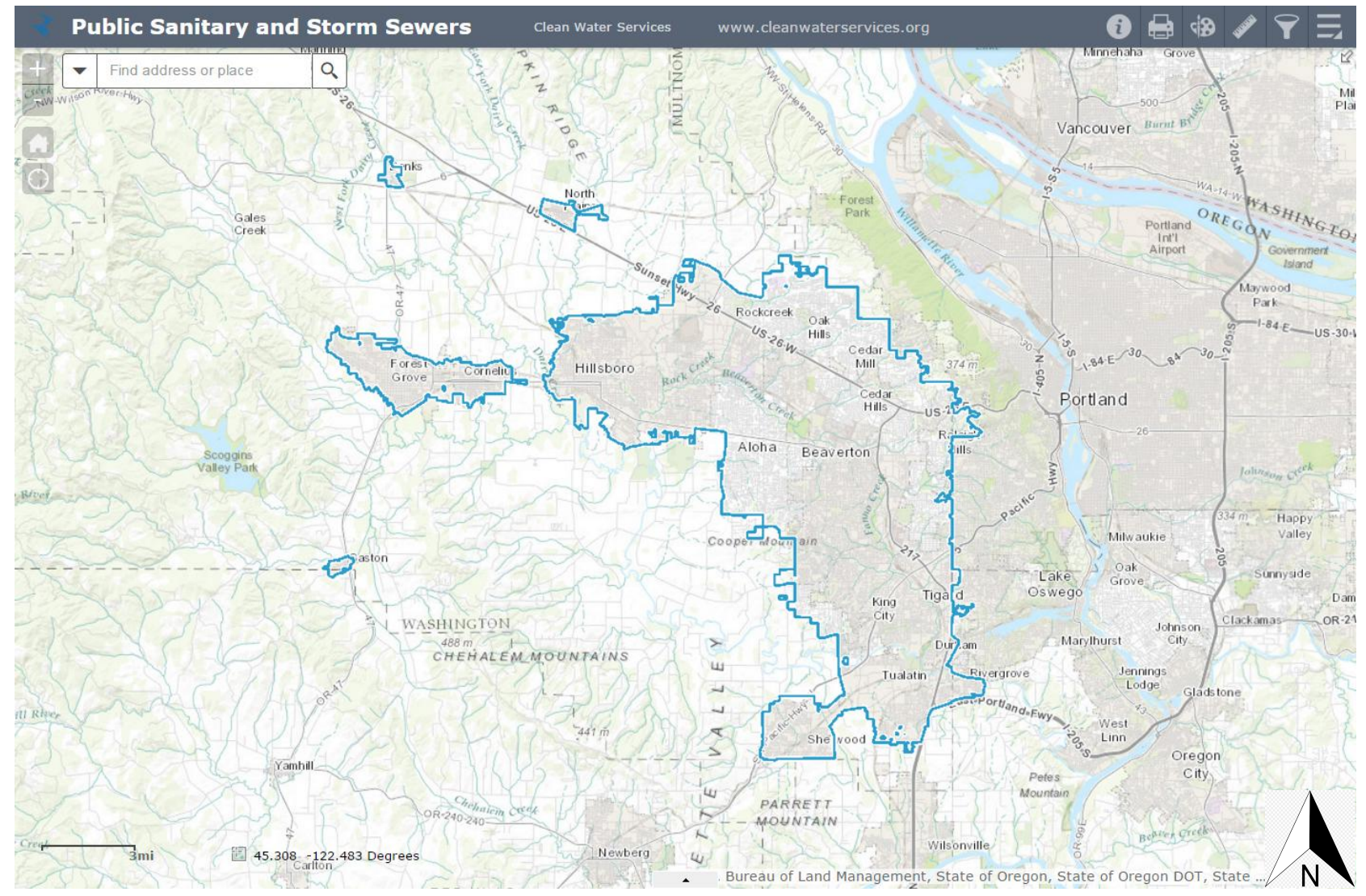

Figure 1: Service area of CWS

return to the river" (Dummer, 2021). While CWS must comply with both federal and local water discharge permits, most of their wetland restoration projects are embarked upon because of internal CWS missions and serving community values. In response to the community surveys (Davis, Hibbits, \& McCaig, 2002) and the creation of the Healthy Streams Plan of 2005, CWS prioritizes projects focused on restoring and preserving the waterways (wetlands, lakes, streams, and rivers) of the Tualatin River Watershed (Clean Water Services, 2019). Along with the Healthy Streams Plan, CWS must follow the rules and regulations set forth by the DEQ National Pollutant Discharge Elimination System Industrial Stormwater Discharge Permit No. 1200-Z, which identifies several water quality parameters that CWS must maintain within their 
wastewater discharge (temperature, $\mathrm{pH}$, nutrient concentrations, heavy metals, suspended solids).

\section{Phase 1: Preparing for field research}

\section{Literature Review}

The idea that planting more mature plants will result in less mortality is not new. A 1979 paper by Cook looks at how different ages and sizes (which are highly correlated) of plants respond to stressors in non-extreme habitats and conditions. The goal was to look at how different genetic adaptations influence the response of these plants within their life stages. His overall findings were that older plants, which are usually larger, are more resilient to stressors and have lower mortality rates when the system is exposed to multiple kinds of stressors. Additionally, he found that the larger the plant, the less likely it was to die after being planted but did not offer exact measurements (Cook, 1979). Both findings are significant when looking at my research project. The study by Cook was not done on restored wetland plants; however, it aligns with the hypothesis that larger, older wetland plants will have lower mortality rates.

In a paper on the relationship between the plant size of vascular epiphytes (plants that grow on other plants but are not a parasite, like ferns) and mortality rates, the authors reached a similar conclusion as Cook in that the larger the plant, the less likely it is to die. This highlights that age and size play a large role in the rates of mortality in different types of plants (Zotz et al., 2001).

In a 2001 study by Clark \& Wilson, the authors found across three different treatment practices (burn, hand removal, mow) that when woody wetland plant percent cover decreased within wet prairies in the Willamette Valley, mortality of those plants increased. The study implies that reduction of percent cover caused or contributed to mortality, as opposed to mortality causing the reductions in percent cover. This showed a relationship between percent cover and mortality rates of species in similar ecosystems, but of different plant physiologies, (the species in this study were woody plants, compared to the herbaceous plants of our study) 
to the Thomas Dairy site (Clark \& Wilson, 2001). This study is helpful to the project because it investigated plant cover in ecosystems similar to that of this project (i.e., wetlands in the PNW).

While there is a multitude of concepts that can be addressed when it comes to wetland restoration, this project is focused on herbaceous plant growth. In a 2002 paper by Cole, the author examines whether assessing herbaceous plant cover is a good indicator of proper wetland function. Total percent plant cover of wetland species is commonly used as one of the main criteria to evaluate if the restoration has been successful or not. This is justified by the fact that when you have a higher percent cover of the desired plant, you have a lower chance of an invasive species establishing, increased short-term surface water storage, and the retention, removal of dissolved elements. It is seen as an indicator of proper maintenance, and correct conditions, as when desirable plants are thriving and growing it indicates that the restoration efforts are succeeding. While these assumptions may be true or not, they don't reference the overall function of the wetland according to Cole. Cole (2002) researched this and found that while total percent plant cover may be effective in reducing invasive species, it did not correlate with other wetland functions such as short-term surface water storage, long-term surface water storage, maintenance of a high water table, transformation and cycling of elements, retention, and accumulation of inorganic sediments. Cole suggests that total basal area (the area of the plant at the point it meets the soil) may be more appropriate to use as an indicator for wetland functions.

Opposingly, the EPA and other researchers suggest, and have had success with, using percent coverage as a tool to indicate wetland function (Fennessy et al., 2002; Wilson \& Mitsch, 1996; Keyport et al., 2019). For example, Fennessy et al. (2002) state that wetland plants are responsive to different conditions and nutrient availability overall and that percent cover provides a solid starting point to investigate the functionality and processes of wetlands. As Cole discusses in his paper, he only looked at six wetland functions in his paper, whereas there have been dozens of more wetland functions identified by other researchers (Hammer, 1992; Smith et al., 1995; Cronk \& Fennessy, 2016).

In the end, we decided that using percent cover for this project was the correct approach. While Cole was correct in his analysis of the use of percent cover having limitations, 
we are utilizing percent cover to track growth of wetland plants, rather than attempting to assess an entire wetland of its function. The difference here being that we are only interested in how the two planting types of the three species grow/die over five years, rather than if a restoration effort is successful.

The Class A recycled water that is currently being applied at the Thomas Dairy site is sourced directly from the wastewater treatment plant to the north, known as Durham Wastewater Treatment Plant. As discussed in the project description section, the site is being irrigated between May and October at a rate of between 302,833-378,541 L/day (A map of the irrigation pipes can be found in Appendix B). This rate is based on the estimated "agronomic rate" for the wetland which means that CWS can irrigate the wetland up until the point before ponding occurs. These limits are based on Oregon Administrative Rules (OAR) Chapter 340, Division 50, and section 40 of the Code of Federal Regulations (CFR) Part 503 (Oregon DEQ, 2021).

By putting that water into the wetland instead of directly into the Tualatin River, CWS has the potential to filter water naturally while reducing costs and increasing ecological function. One such way is by reducing the overall temperature of the stream, as effluent entering the Tualatin River must be $77^{\circ} \mathrm{F}$ or cooler (Sturdevant, 2006). When water enters wetlands from treatment facilities, it is not required to be at the permitted stream temperatures. However, as the water will either move slowly on the surface, or seep into the soil it has enough time to reduce in temperature so that when it enters the stream, it is meeting permit requirements (Kadlec, 2006). In this case, CWS has conducted modeling which indicates that applying the reuse water at the current rates will not reach groundwater, which has been shared with DEQ.

While waterbodies such as the Tualatin River interact with groundwater, wetlands function effectively to recharge groundwater aquifers and water levels. This is because the slowing down of the water in a wetland allows more time for the soil to become saturated. As the soil is saturated there is more of an opportunity for that water to seep lower down through the soil and rock levels where it can eventually interact and become part of groundwater aquifers or springs (Cowardin, 2013). This means by restoring the wetland and increasing the 
amount of water going into it, the surface-water-to-groundwater exchange could become closer to levels found in naturally functioning wetlands in the area.

According to a 2015 paper by Patrignani and Ochsner, the software tool known as Canopeo, which can be accessed via mobile devices, is an effective, efficient, and accurate tool to capture the percent cover of vegetation. They analyzed the accuracy of Canopeo against a wide range of different species of plants such as grasses, corn, and sorghum. Other authors have used the application to survey even more species of plants such as cotton (Graham et al., 2019), soybeans (Shepherd et al., 2018), and canola (Graham et al., 2019). These papers found the Canopeo application to be both fast and reliable. When compared to other methods of collecting percent coverage such as SamplePoint, Patrignani and Ochsner (2015) concluded that Canopeo was comparable in accuracy, with a faster image processing time. Additionally, the authors state that using aerial imaging may result in more consistent results in larger plants.

\section{Research Questions and Hypothesis}

This research project will identify if Clean Water Services and other wetland restoration managers should consider replanting restoration wetlands with more mature and larger plants (containerized) or continue with the current practice of using smaller, juvenile plants (plugs). My research questions are:

i. Does planting in restored wetland areas with larger and more mature herbaceous plants (in \#1 containers) result in more ground cover percentage after five years of growth when compared to traditional planting methods using juvenile plant plugs when they start with the same relative basal area?

ii. Is there a significant difference in mortality rates per area between containerized herbaceous plants versus immature herbaceous plant plugs in these restored wetlands? 
iii. Is it more cost effective to utilize containerized plants of the three Carex species compared to plugs when looking at percent coverage after five years of growth in the ground?

If these three questions are answered with solid data and analysis, the information can be used directly and immediately on current and future wetland restoration projects. If it is found that plugs are the better option, we can expect CWS and others to continue using plant plugs in restoration projects. Based on the literature, I hypothesize that the more mature plants will end up with a larger total percent coverage. Additionally, I hypothesize that the plugs of some, if not all species will have a higher mortality rate when compared to the containerized plants. I believe that this will be due both to high mortality rates within the juvenile plants and higher resiliency to harm or disturbance in the more mature plants, and the plants' rates of growth will not be as impeded by environmental factors. Lastly, I hypothesize that planting wetlands with containerized plants will be more cost-effective in the long-term as the cost per square foot of cover will be less.

\section{Experimental Design}

The design of this project is to test the hypothesis that installing containerized plants of three wetland herbaceous species (Carex obnupta, Carex stipata, Carex unilateralis) is more effective when attempting to establish wetland flora communities on Clean Water Services managed wetland restoration projects. Six subplots will be planted (i.e., containerized $C$. stipata, plug C. Stipata, containerized C. obnupta, plug C. obnupta, containerized C. unilateralis, and plug $C$. unilateralis) within 13 plots at the Thomas Dairy site. (The location of the site in relation to the surrounding area can be seen in Figure 2.) This will result in a total of 78 subplots, each $100 \mathrm{ft}^{2}(10 \mathrm{ft} \times 10 \mathrm{ft})$. The location of the 13 plots has been randomly generated using geographic information system (GIS) software, while avoiding obstructions at the site such as trees, water lines, or site boundary lines. Moreover, the orientation of each of the plots 
will be randomized. The location of the subplots within each plot will be randomly assigned as well.

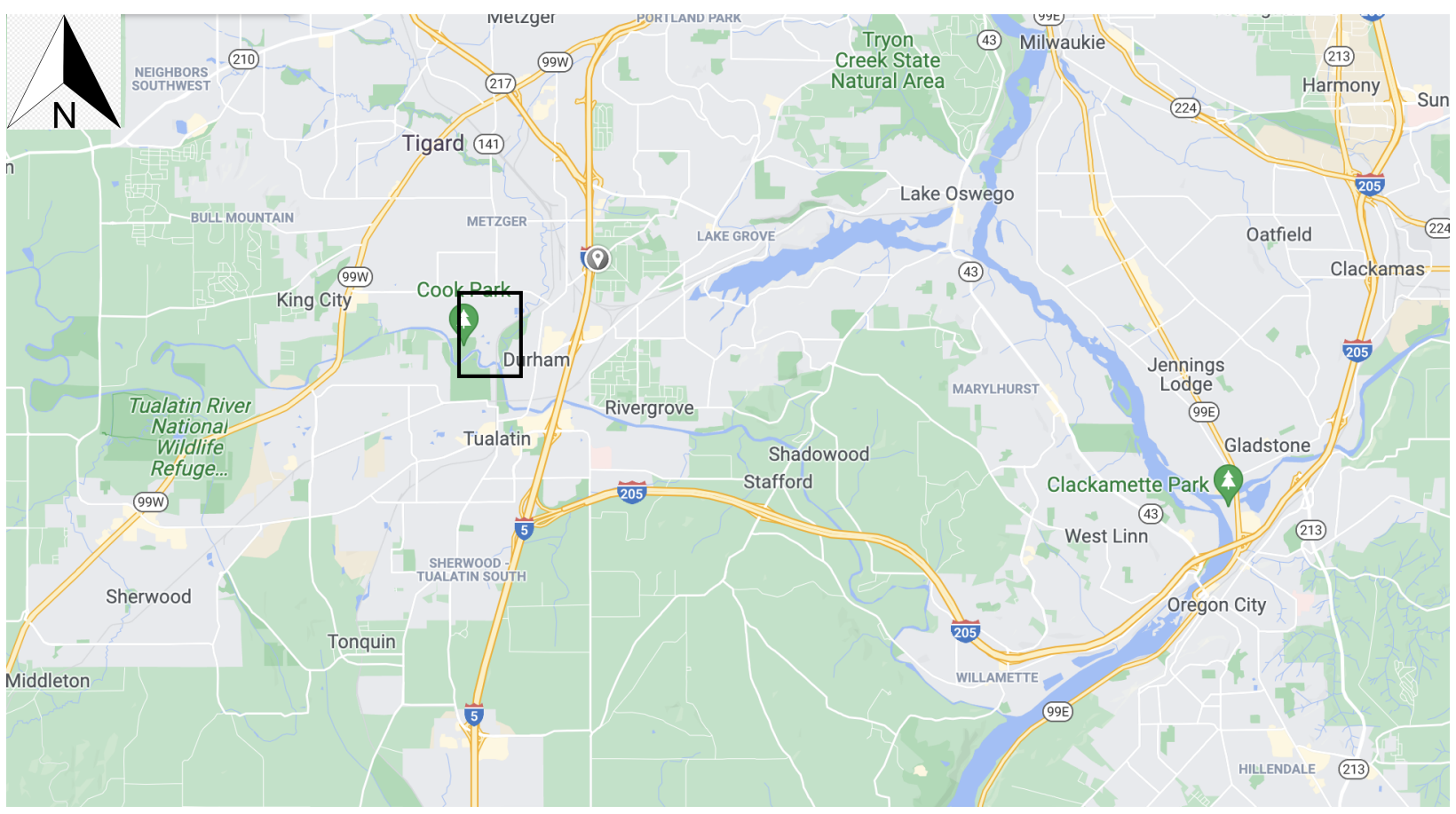

Figure 2: Map of area the Thomas Dairy is situated in with specific area outline in black rectangle

Figure 3 shows plot locations created by the GIS team at CWS. The entirety of the Thomas Dairy site is about three times larger than our study area. We chose the midsection of the wetland because the northern third is drier and does not always meet minimum requirements to be categorized as a "wetland". The southern edge is wetter leaving much of the area flooded where the plants of this study could not survive, and would not be planted under normal restoration efforts. This variation in moisture in the middle of the site allows us to observe the effects of soil moisture on plant establishment. As Figure 3 shows, we created a buffer of at least 10 feet around each plot to ensure that the plants from other plots would not encroach on each other. The white area in the map (in the map key, this is the area notated as: valid area for point placement) is where the plot center could have been placed, while still maintaining a 10-foot buffer from any obstacles, such as the irrigation pipes, or boundaries of the site. Within each plot, the subplots will be separated by five feet from each other and oriented in two sets of three, to make a rectangular shape, as can be seen in Figure 4. Each plot 


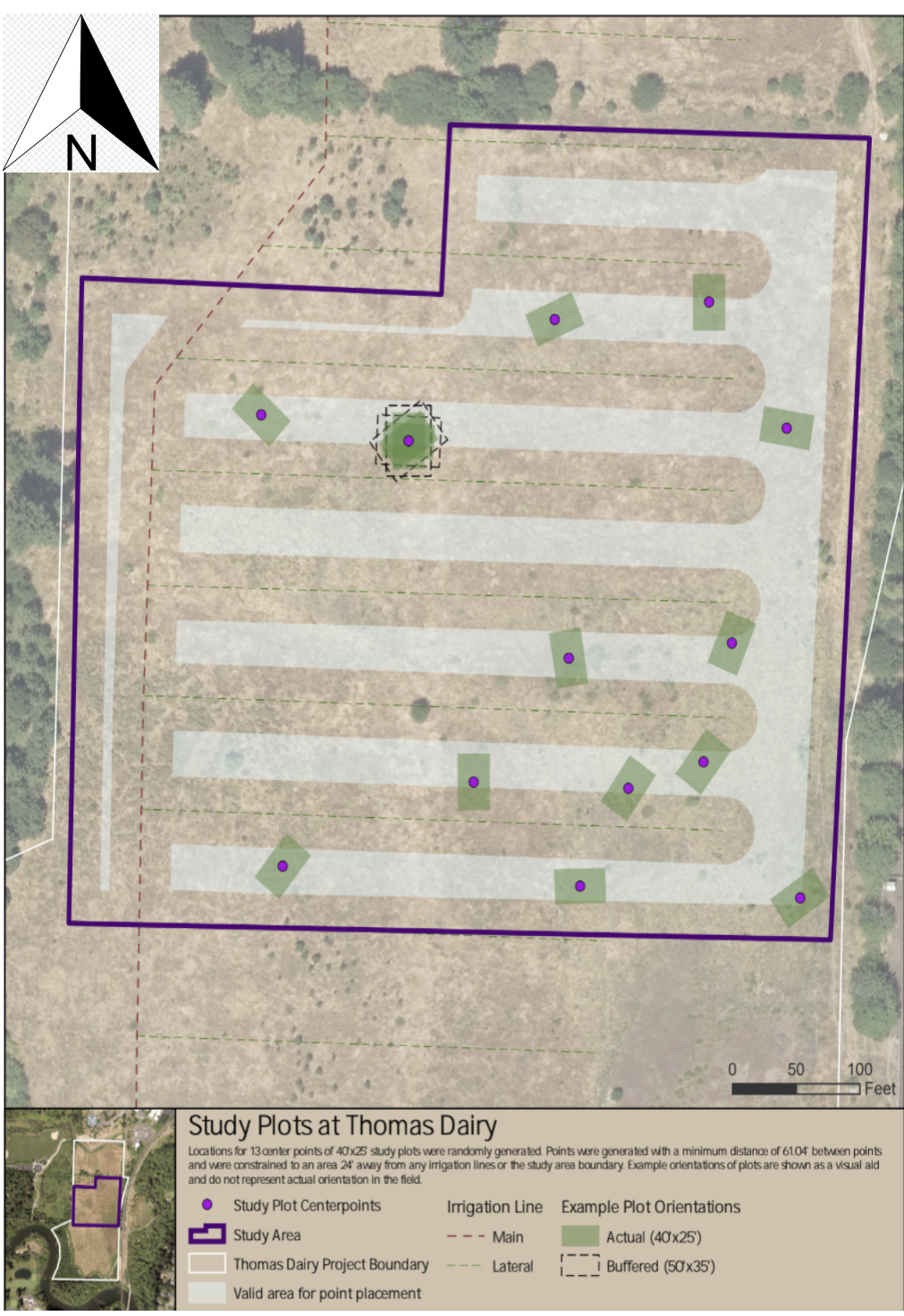

Figure 3: Map of plot locations in Thomas Dairy Wetland is $40^{\prime} \times 25^{\prime}$ which allows each subplot $\left(10^{\prime} \times 10^{\prime}\right)$ to have a buffer of at least five feet. Each containerized plant is about three times the basal area of each plug, according to the nursery experts who grow these species (Elteto et al., 2021). Subplots planted with juvenile plants will contain 81 plugs, spaced one foot apart, including to the edges of the subplot. To attempt to have all subplots contain the same amount of plant basal area, the subplots containing the mature plants will each contain 27 plants that are further evenly spaced.

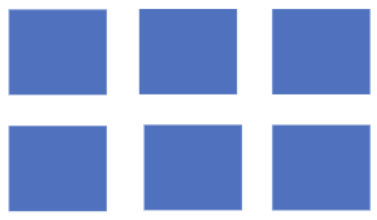

Figure 4: Model of subplot orientation within plots

\section{Species Selection}

John Goetz III and CWS project leaders compiled a list of all the herbaceous wetland plants that CWS currently uses on wetland restoration sites. With that list, John and I identified only plants that are commonly used (those that are used on most projects). We further narrowed our selection down to these three Carex species as they would be available through nurseries by this year, or next year at the latest. We were left with the three Carex species that 
have become the focal point of this study. The three species of Carex (C. obnupta, C. stipata, and C. unilateralis) selected are commonly and abundantly used in wetland restoration projects by CWS in the Tualatin River Watershed, as well as elsewhere in the Pacific Northwest (PNW) (Van Der Valk et al., 1999; Hough-Snee, 2010; Clark \& Wilson, 2001).

C. obnupta is an evergreen obligate wetland sedge that spreads primarily through rhizomatous processes, though it can further propagate via seeds. It has been found thriving in many conditions including, but not limited to, stream and lake edges, tidal marshes, temperate rainforests, and wet meadows (Hough-Snee, 2010). C. obnupta form dense bunches that can easily spread over a wetland in the correct conditions (amount of sunlight, precipitation, and soil nutrients). The natural range for C. obnupta is from British Columbia to northern California, mostly west of the Cascade Mountains, where there is more available water (Wilson et al. 2008). When fully mature, it usually stands at around three feet high. While it is adapted to fine and medium soils, -the species can survive in coarse soils, although it will not thrive and will have a higher rate of mortality in coarse soils. C. obnupta has medium tolerance to calcium carbonate, which is most important when planting in land that was previously of agriculture use. Calcium carbonate is commonly added to agricultural land as a fertilizer filler, or for $\mathrm{pH}$ control (Yadav et al., 2021), though calcium carbonate does occur naturally in many soils (Durand et al., 2018). It needs a soil pH of 5.5-7.0. While it grows best and fastest in full sun, it is shade tolerant. $C$. obnupta has a relatively rapid growth rate compared to the other two species. It needs $40-65$ inch/y of precipitation-though this is less important, as the Thomas Dairy site is irrigated nearly half the year and receive rain for most of the other half of the year (USDA, 2021).

C. stipata, unlike C. obnupta, is a deciduous sedge, though like $C$. obnupta, it grows in bunches (Chayka, 2021). An obligate wetland species, it has spread to many wetland habitats around the globe, such as most of North America, parts of Europe, and portions of eastern Asia (Wilson et al., 2008). When mature it can stand $3.5 \mathrm{ft}$ high. It is adapted to fine and medium soils, not coarse soils. Like C. obnupta, it has medium tolerance to calcium carbonate. It needs soils that have a range of $\mathrm{pH}$ of 4.9-7.9. C. stipata is shade tolerant yet does best in full sun. It has a relatively slow growth rate which was one of the leading factors of having a five-year 
study. It needs 12-50 inch/y of precipitation. It can withstand partial flooding, but will die off if left in standing water (Magee \& Kentula, 2005).

C. unilateralis is not present in much scientific literature. However, we do know that this sedge is commonly found in wet prairies and ditches. It is 12-30" tall, has yellowish-green foliage, is densely bunched, and has compact flower heads (Carex, 2021). It is deciduous and will fully or partially die back during winter. Burning does not increase mortality but does decrease above-ground biomass, which is important as burning has occasionally been practiced by CWS at Thomas Dairy (US Fish and Wildlife Service, 2010; Wilson et al., 2008).

\section{Replicates and Field Design}

This project uses three different Carex species (Carex stipata, Carex obnupta, and Carex unilateralis) that are frequently used in CWS projects and are further used by other organizations in the PNW (Wilson et al., 2008). We decided to use these three because of their widespread use, and because they are each unique and have different growth rates and size limits. We hope that by using three distinct species, we lower the likelihood that our plots have unexpected deaths due to disease or some unknown species-specific environmental intolerance.

To determine the number of plots needed, it was necessary to project into the future what the expected outcomes would most likely be. This was done to maximize the likelihood of project success. For each of the three species, I talked to experts in the field (nursery managers, project managers and contractors) on what their observed growth has been after five years of plant growth. For example, it is estimated that after five years, we could expect an average Carex obnupta plug to cover roughly $1.5 \mathrm{ft}^{2}$, whereas the containerized version could be expected to cover roughly $3.5 \mathrm{ft}^{2}$. I collected information from the experts on what percentage

of plants they have observed die by species and plant size, along with their estimated standard deviation of growth at the end of five years (Elteto et al., 2021).

With all this information, I was able to execute a power analysis (power.t.test) in $\mathrm{R}$ studio to determine how many plots we should create. The entire mathematical process and 
" $R$ " code can be found in Appendix C. With this test, I was able to determine that the highest number of plots needed for any of the three species was 13 with a power level of at least 0.90 . To find that number, signified as $\mathrm{n}$, I needed to know both the delta (the difference between the means of two groups) and the standard deviation. I used the data supplied by the experts to calculate " $\mathrm{n}$ " accordingly for the three different plants, and plant sizes. The goal is to have a significance level of 0.05 or lower, and a power level of 0.90 or higher. While the calculation revealed that for two of the three plant species, 13 plots were more than needed for a power level of 0.90, Carex stipata (10), and Carex unilateralis (12), Carex obnupta required 13 plots to reach that power level. Since we have 6 different planting types (three species at two sizes), needing 13 plots each, we decided to position all six planting types into each of the 13 plots, resulting in a total of 78 total subplots.

\section{Site Selection}

During the planning stages of this project, John Goetz III and I investigated four different sites that we could have used for this study: the Davis Tool site in Hillsboro, the Jackson Bottom site in Hillsboro, the West Bethany Creek site in the North Bethany area, and the Thomas Dairy site in Tigard. All four of these sites are either owned by CWS or CWS is the land steward for them. After visiting each of the sites, we eliminated both the Jackson Bottom site and the West Bethany site; the former because it is a large site with access issues and - the latter site because there is heavy deer activity and we were concerned that the deer may pull the experimental plugs out of the ground. We contemplated using both the Davis Tool and Thomas Dairy sites for our study, but decided that to avoid unnecessary variables and located the study within one site. We eventually chose to conduct the study at the Thomas Dairy site for a few reasons: first, the site is flown by drones consistently, meaning that including the use of drones for image collection could be somewhat seamless. Second, the site has easy access and was relatively close to both myself and John Goetz III. Thirdly, the property is under the ownership of CWS which simplifies access for plot installation and monitoring. Lastly, the implementation of a reuse water irrigation project at the Thomas Dairy site guaranteed that the hydrology will be 
adequate to support wetland vegetation year-round, which means that the chance of a drought killing the plants was greatly reduced. More information on the irrigation at Thomas Dairy is located in the next section.

\section{History and Information of Site}

To the best of our knowledge, the Thomas Dairy site obtained its name because from the mid-20th century up until CWS purchased the land in the early 2000s, it was a dairy farm. Before becoming a dairy farm, it is suspected that the land was either an emergent wetland, wet prairie, or oak habitat. By 2008, the first plants were being planted at the site in an attempt by CWS to restore what was assumed to be the area's natural function, a wetland.

Since 2008, annual projects have followed a seasonal schedule to continue to attempt to restore the Thomas Dairy site. In winter, CWS installs woody plants around the perimeter of the property to create a natural hedgerow marking the property boundary. In spring they target weed control via hand pulling, mowing, and herbicide application with some limited seeding and planting of wetland plugs. In summer they have more targeted weed control via hand pulling, mowing, herbicide application and a couple of prescribed burns. During the summer CWS also conducts vegetation monitoring and Unmanned Aircraft Systems (UAS) flights, as the conditions for flying drones are the best. In fall they have more targeted weed control via hand pulling, mowing, and herbicide application. This is the season when most of the planting and seeding is done.

There are two primary reasons that the Thomas Dairy site has been undergoing restoration since at least 2008. First, the southwestern edge of the property runs along a stretch of the Tualatin River. This allowed CWS to create a riparian forest where they planted trees along the river, providing shade on the river, allowing them to accrue shade credits, which can be traded for other water quality credits to meet permitting requirements (Oregon Secretary of State, 2015). The second reason is that most of the site was delineated as a jurisdictional wetland, meaning that it falls under the guidance of the Healthy Streams Plan of 2005. Because of both community and internal organizational values, the restoration and 
preservation of wetlands-along with other water systems in the Tualatin River Watershedwere prioritized (Smith \& Ory, 2005).

Because the three Carex species in this study are known to only tolerate certain soil

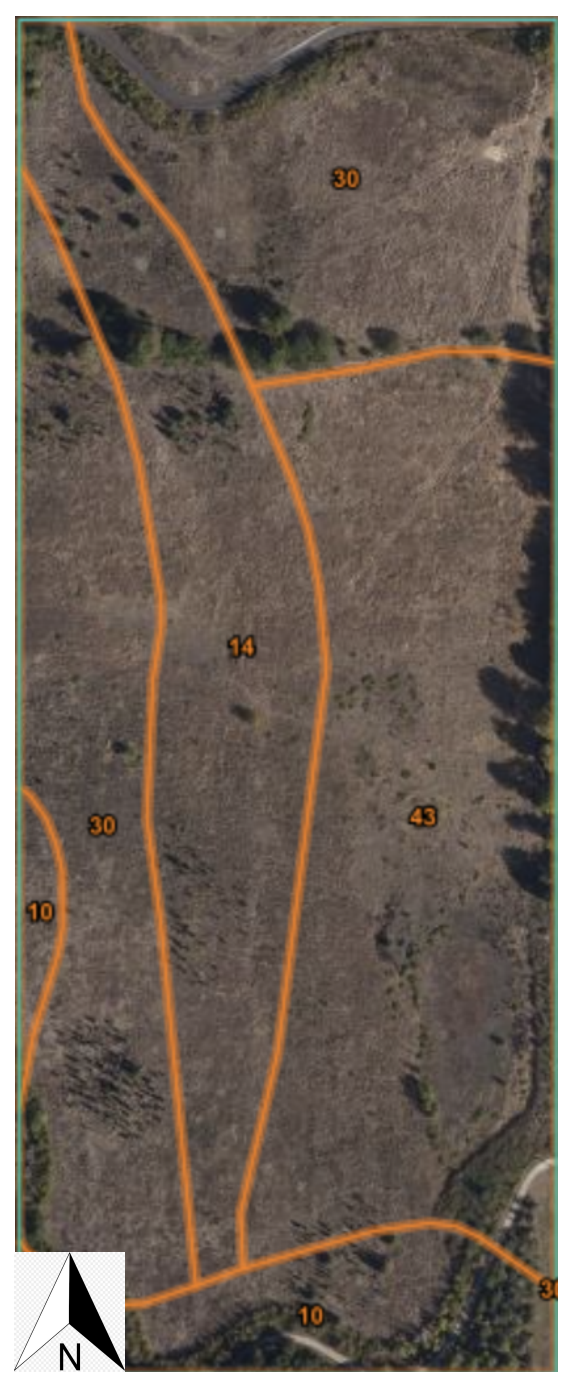
types and soil characteristics, it was pertinent to obtain information on soil types, along with other soil data. This information could also be

Washington County, Oregon (OR067) Washington County, Oregon (OR067)

\begin{tabular}{|l|l|r|r|}
\hline $\begin{array}{c}\text { Map } \\
\text { Unit } \\
\text { Symbol }\end{array}$ & \multicolumn{1}{|c|}{ Map Unit Name } & $\begin{array}{c}\text { Acres } \\
\text { in } \\
\text { AOI }\end{array}$ & $\begin{array}{c}\text { Percent } \\
\text { of AOI }\end{array}$ \\
\hline 10 & $\begin{array}{l}\text { Chehalis silt loam, } \\
\text { occasional } \\
\text { overflow }\end{array}$ & 2.2 & $9.3 \%$ \\
\hline 14 & Cove clay & 5.0 & $21.0 \%$ \\
\hline 30 & $\begin{array}{l}\text { McBee silty clay } \\
\text { loam }\end{array}$ & 8.8 & $37.4 \%$ \\
\hline 43 & $\begin{array}{l}\text { Wapato silty clay } \\
\text { loam }\end{array}$ & 7.6 & $32.3 \%$ \\
\hline Totals for Area of & $\mathbf{2 3 . 6}$ & $\mathbf{1 0 0 . 0 \%}$ \\
\hline Interest & & \\
\hline
\end{tabular}

Figure 5: Soil type map of Thomas Dairy

important for future research and analysis. Figure 5 shows the soil map of the Thomas Dairy area (Soil Survey Staff, 2021). As can be seen on the map, there are four distinct soil zones within Thomas Dairy site with three of soil types (soil zones 14, 30, 43). Those soils are all considered fine, or moderately fine, which means that the Carex species of this study should not have a problem growing based solely on soil texture (Peterson, 1999). 
In order to obtain more information about the soil, I collected soil samples of the site. We did this for two primary reasons: first, since CWS is irrigating the site with non-potable reuse water, they have a plan to monitor nutrient flows and changes within the wetland (Oregon Department of Environmental Quality, 2021); second, with the soil data obtained from these samples, and with future soil samples, it will be possible for CWS to look at possible influences affecting the Carex plots. While this goes beyond the scope of this project, it is easy to envision a future researcher looking at the data collected from this project, as well as the soil sampling data and coming to interesting conclusions surrounding soil types/nutrients, Carex mortality or growth as well as tailor native plant species to suitable soil types.

On July 29, 2021, Aubrey Harris and I collected 20 soil samples from ten locations in the Thomas Dairy site. These locations were randomly generated by software utilized by the CWS GIS team. We were planning on sampling from as many as 16 locations, yet due to heavy soil compaction, we were unable to retrieve samples from six of the selected locations. Figure 6 shows the planned 16 locations for soil sample collection. We were able to collect from each of these locations except for 1, 2, 3, 4,7 , and 14. We were unable to collect from those locations due to heavy soil compaction around 4-6 inches in the soil. We collected two soil samples per location, one from 0-12 inches, and one from 12-24 inches. While this is considered only two samples per location, we mixed the soil from about five holes to collect enough soil for analysis at each depth, per location. The soil samples were analyzed for nutrients, soil $\mathrm{pH}$, and organic matter percentage, which can be seen in the averages

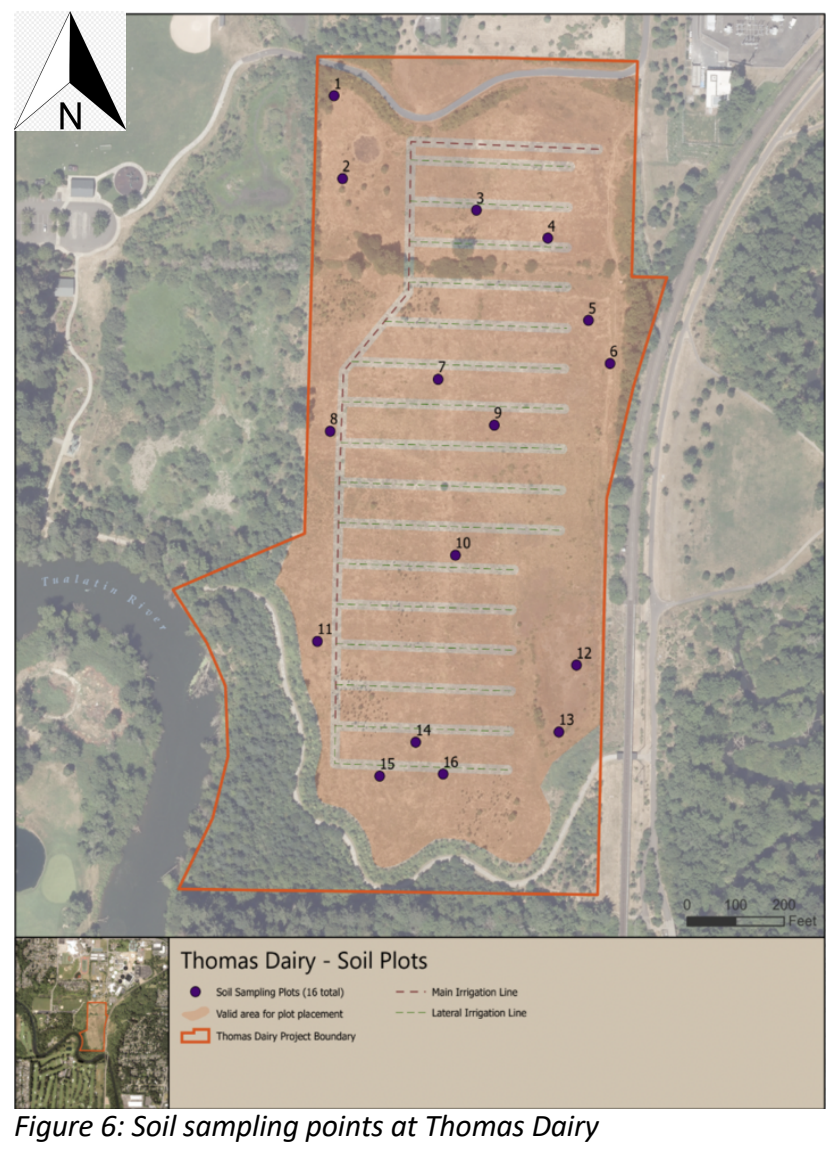
for the two depths in Table 1. P1 in Table 1 refers to available phosphorus in the soil, whereas 
P2 refers to the total amount of phosphorus. Appendix A contains all the soil sample test results completed by Midwest Laboratories.

Table 1: Notable findings from soil sample analysis from Thomas Dairy

\begin{tabular}{|c|c|c|c|c|c|c|c|c|c|c|}
\hline Name & Depth (in) & Organic matter \% & P1 ppm & P2 ppm & K ppm I & Mg ppm & Ca ppm & Na ppm & $\mathrm{pH}$ & Nitrate-N ppm \\
\hline $5 A$ & 0-12 & 2.8 & 15 & 25 & 62 & 387 & 1566 & 50 & 5.8 & 1 \\
\hline $5 C$ & $12-24$ & 1.6 & 5 & 6 & 98 & 917 & 2379 & 121 & 6.2 & 2 \\
\hline $6 \mathrm{~A}$ & $0-12$ & 3.5 & 21 & 37 & 84 & 371 & 1766 & 76 & 5.4 & 2 \\
\hline $6 C$ & $12-24$ & 1.5 & 12 & 15 & 126 & 952 & 2624 & 175 & 5.9 & 1 \\
\hline $8 \mathrm{~A}$ & $0-12$ & 3.4 & 27 & 53 & 132 & 341 & 1856 & 40 & 5.8 & 1 \\
\hline $8 C$ & $12-24$ & 1.7 & 9 & 21 & 81 & 316 & 1471 & 45 & 6 & 1 \\
\hline $9 A$ & $0-12$ & 3.7 & 20 & 36 & 75 & 460 & 1787 & 61 & 6.1 & 1 \\
\hline $9 \mathrm{C}$ & $12-24$ & 1.5 & 7 & 23 & 91 & 999 & 2427 & 157 & 6.7 & 1 \\
\hline $10 \mathrm{~A}$ & $0-12$ & 3 & 14 & 30 & 136 & 286 & 1622 & 29 & 5.5 & 2 \\
\hline $10 \mathrm{C}$ & $12-24$ & 1.7 & 11 & 22 & 97 & 307 & 1590 & 44 & 5.8 & 2 \\
\hline $11 \mathrm{~A}$ & $0-12$ & 3.5 & 23 & 59 & 98 & 335 & 1980 & 47 & 5.6 & 1 \\
\hline $11 C$ & $12-24$ & 2.5 & 29 & 52 & 67 & 365 & 2131 & 33 & 5.8 & 1 \\
\hline $12 \mathrm{~A}$ & $0-12$ & 3.5 & 17 & 34 & 113 & 922 & 2621 & 148 & 5.9 & 1 \\
\hline $12 \mathrm{C}$ & $12-24$ & 1.8 & 8 & 23 & 120 & 1188 & 2819 & 154 & 6.6 & 1 \\
\hline $13 \mathrm{~A}$ & $0-12$ & 2.9 & 14 & 31 & 53 & 314 & 1339 & 68 & 5.6 & 2 \\
\hline $13 C$ & $12-24$ & 1.3 & 3 & 5 & 86 & 768 & 1851 & 130 & 6.3 & 2 \\
\hline $15 A$ & $0-12$ & 3.5 & 30 & 55 & 78 & 272 & 1744 & 31 & 5.6 & 2 \\
\hline $15 \mathrm{C}$ & $12-24$ & 1.6 & 25 & 54 & 61 & 262 & 1580 & 34 & 5.7 & 2 \\
\hline $16 \mathrm{~A}$ & $0-12$ & 3 & 33 & 60 & 164 & 199 & 1689 & 25 & 5.5 & 2 \\
\hline $16 \mathrm{C}$ & $12-24$ & 2 & 23 & 41 & 151 & 185 & 1680 & 23 & 5.7 & 2 \\
\hline
\end{tabular}

Concurrently to this project, reuse water was released to the Thomas Dairy site. Reuse water is treated, non-potable water that is usually discharged from the Durham Wastewater Treatment Plant into the Tualatin River. The treatment plant is located a few hundred feet to the north of Thomas Dairy, allowing it to be the perfect wetland site to test out irrigating with reuse water before moving onto more logistically challenging. The water was turned on in early August of 2021 . The current agronomic rate of flow is between $302,833-378,541 \mathrm{~L} /$ day and is only on from dusk to dawn. The water is entering the wetland via a sprinkler system that was installed in July of 2021. This system will be utilized yearly from May-October for at least the five years of this project. 


\section{Data Collection}

$\underline{\text { Rationale }}$

As was discussed in the literature review, percent cover of favorable plants within wetlands is an indicator that is recommended for monitoring wetland function by the EPA (Fennessy et al., 2002), as well as by other authors (Wilson \& Mitsch, 1996; Keyport et al., 2019). Using percent cover is a relatively labor-efficient method of establishing growth rate. Growth could additionally be measured by biomass, height, or basal area. Because of this, we have decided to use it as a measure of growth of the three Carex in this study and the method for data collection is focused on this variable. As discussed earlier, even if percent cover of plants was not valid for assessing wetland function, we would still use it in this project as it is a clear and direct way to monitor growth of plants. Additionally, this is useful as CWS can use existing schedules of vegetation monitoring and UAS specialists and equipment to capture the percent coverage of the plants.

Drones will be utilized to capture the images for a few of reasons. First, each image must be of an entire subplot (10 ft x $10 \mathrm{ft}$ ) which would be difficult to achieve without the use of a drone. Second, the drones use a program that automates their flight, guaranteeing images of each subplot are being taken from the same location and elevation each time. Lastly, the drones are equipped with high quality digital cameras (if we were capturing the images by hand, it would be done on an iPad), with the option over time to equip with higher quality cameras. This is important because the higher the resolution of the image, the more accurate measurement of the percent coverage is when processed through Canopeo.

An additional reason we decided to rely on an application rather than people to calculate the percent cover is consistency. Because the application runs off a program, it will give consistent results. Hand counting the percent cover would likely not give consistent results. Images will be captured over five years, and it would be likely that more than one person would have the job of hand counting percent coverage and two or more people could have different results even when looking at the same image. For these reasons we decided to use Canopeo as the means to calculate percent cover. 
As the containerized plants are larger, there will be three times less of them in this project compared to plugs. To compare the mortality rates, we will calculate a simple percentage. For example, if a ratio of 1:1 containerized plants to plant plugs die, the plots with containerized plants would have a mortality rate three times that of plugs as there are three times more plugs in this project than containerized plants.

\section{Canopeo Information \& Calibration}

The application Canopeo was chosen to process the images and calculate the percent cover of the subplots because according to several papers written within the last five years, it is an accurate and efficient tool (Patrignani \& Ochsner, 2015). Canopeo works by analyzing the pixels within images for the ratios of Red/Green, Blue/Green and the excess green index. After an image is run through the application, pixels that are within the green canopy are shown as white pixels, whereas those failing to meet the criteria for green canopy are shown as black pixels, resulting in a binary image. Below is an explanation of the calibration of Canopea by Patrignani and Ochsner, 2015:

Fractional green canopy cover ranges from 0 (no green canopy cover) to 1 (100\% green canopy cover). The classification of green canopy is based on the following criteria:

$$
\mathrm{R} / \mathrm{G}<P_{1} \text { and } \mathrm{B} / \mathrm{G}<P_{2} \text { and } 2 \mathrm{G}-\mathrm{R}-\mathrm{B}>P_{3}
$$

where $P_{1}$ and $P_{2}$ are parameters that typically have a value near 1 to classify pixels that are predominantly in the green band ( $500-570 \mathrm{~nm})$, and $P_{3}$ is a parameter that sets the minimum excess green index, which typically has a value around 20 to select green vegetation. The default parameter values for Canopeo are $P_{1}=0.95, P_{2}=0.95$, and $P_{3}=$ 20. (Patrignani \& Ochsner, 2015)

I further calibrated the software to 1.07 (the application allows for adjustment from 0.8-1.1). | landed at 1.07 as when the image was run through at that calibration, it matched closely to the same percent cover that was found through hand counting of one image (for this project, three images must be used). According to my hand count results, adjusting the software to 1.07 resulted in the most accurate analysis of the image. Adjusting the number higher allows the 
software to include a wider range of pixels that are considered "green canopy". While I initially used one image of $C$. obnupta to calibrate Canopeo, I suggest that CWS uses three images of each species to calibrate before processing images collected for this study.

\section{$\underline{\text { Image Capture }}$}

Three times a year (April, July, and October) digital photographs of each subplot will be captured by a camera mounted on a drone with the gimbal positioned at 90 degrees, at a height of 25 feet. Each image will be captured from the center of the subplot, which will be repeated each time with assistance from DJI Ground Station Pro flight software to ensure that the drone is in the same position each time.

\section{Image Preparation}

Because Canopeo cannot discern between plant species, before processing the images,

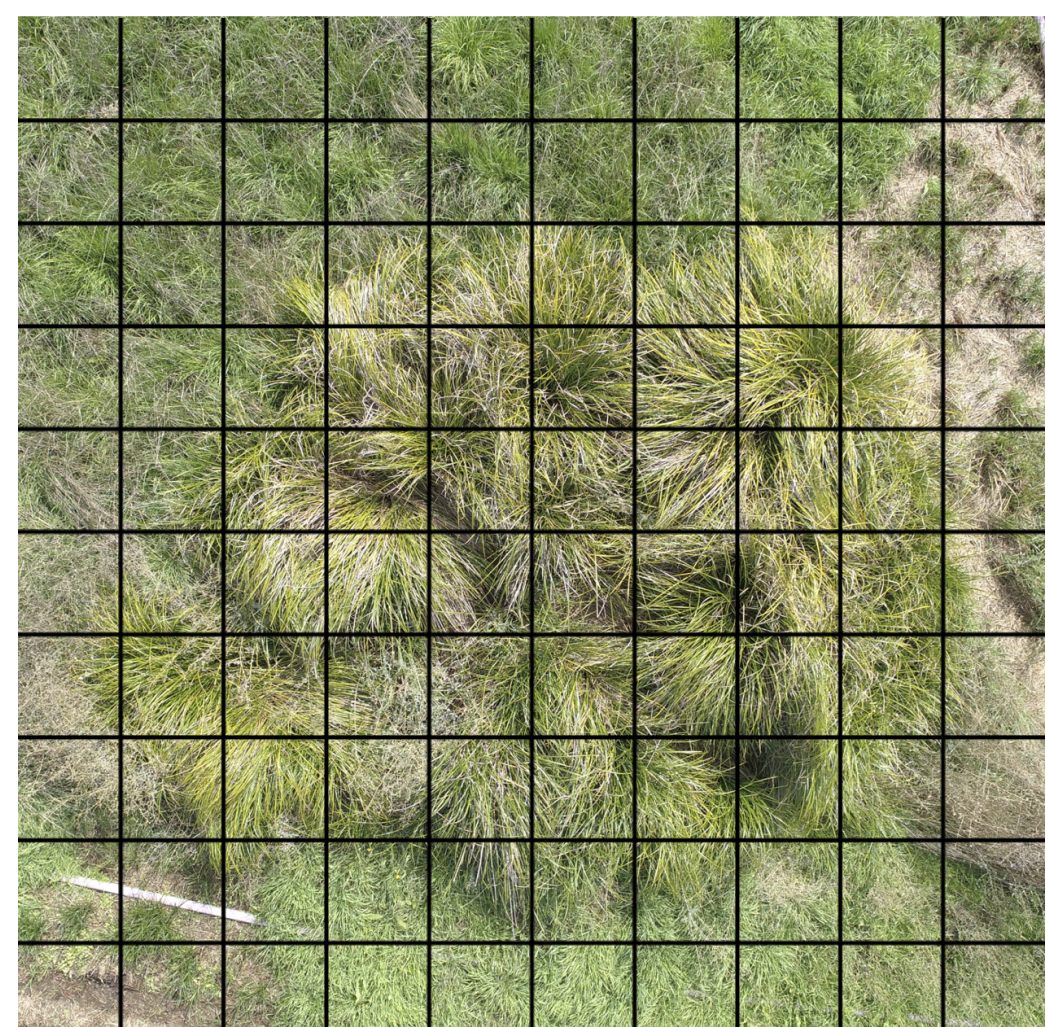

Figure 7: Carex obnupta image captured at 25' with a $10 \times 10$ grid the living material around the sedges must be blacked out in some way. One way to do this is to crop the image so only the $10 \mathrm{ft}$ $x$ 10ft subplot is in the image, and then use the Smart Lasso tool in macOS Preview (or something comparable) to eliminate the green space that is not the sedges.

To illustrate this process Figure 7 is a digital photograph taken by drone-mounted camera in mid-September of 2021 at a 
height of 25 feet. This image shows $C$. obnupta and surrounding vegetation. I further cropped the image until it was capturing what appeared to be a $10 \mathrm{ft} \times 10 \mathrm{ft}$ area (because this image was used for calibration, the size is unimportant). It should be noted that the corners of each subplot will be clearly marked in the field, so those doing the cropping of the images will be able to accurately identify the boundaries of each subplot every time. To test the accuracy and adjustment of Canopeo, I used the traditional method of overlaying a 100 square grid on the image to calculate the percent coverage of the Carex. In this case, I concluded that the percent coverage by Carex is around $42 \%$.

When I ran the exact image (without the grid) through the Canopeo app, I ran into a problem; the app identified most of the grass around the Carex, yet not the Carex itself as live foliage. When I adjusted the setting to additionally capture the greens of the Carex, the app overestimated the percent cover by almost double. Figure 8 illustrates my solution to this problem and is what is mentioned at the beginning of this section. I used the previously described software tools to delete everything that was not the Carex species of interest within the plot photo. Finally, I ran this altered image through Canopeo and had to adjust the setting to 1.07 , wherein I attained the result of $41.97 \%$ coverage. Figure 9 is what the Carex patch in Figure 8 looks like after being run through the program. Please note that the hand count adjustment of the Canopeo software was only completed for $C$. obnupta and only for one image. It will be necessary for CWS to run through the same steps I have outlined here for both C. stipata and C. unilateralis before attempting to process the data collected. This can be completed any time before the images are run through the Canopeo software. 
When run through the Canopeo software and adjusted to 1.07 , the percent coverage is accurate to what I found by hand counting, which was the way that I ground-truthed the software. Before adjusting to 1.07 , the software calculated the percent cover as $24.85 \%$, which is far off from the $42 \%$ found by hand counting. Based on my hand counting, the saturation level of 1.07 is most accurate for $C$. obnupta, though three images for each species are recommended. As all images are captured from the same height, and a standardly cropped, Canopeo will give the same results, regardless of the person using it, if my instructions are followed.

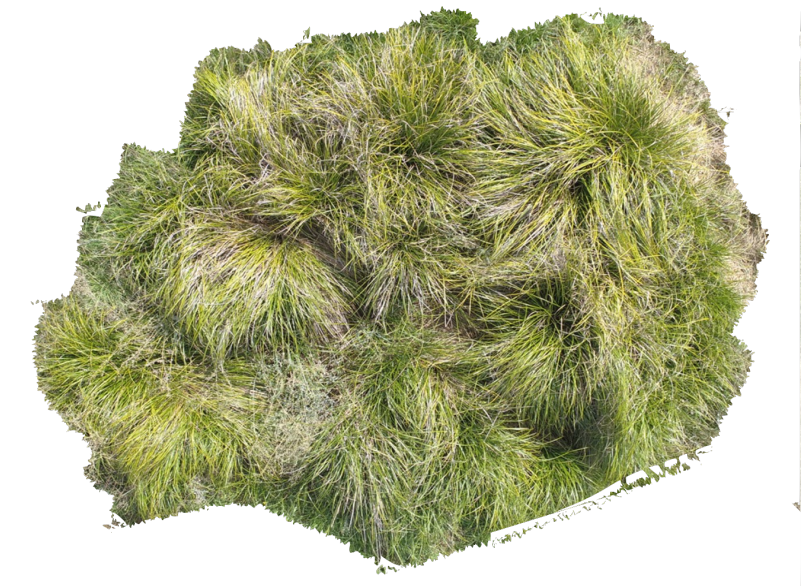

Figure 8: C. obnupta image after living matter not of species is removed

Phase 2

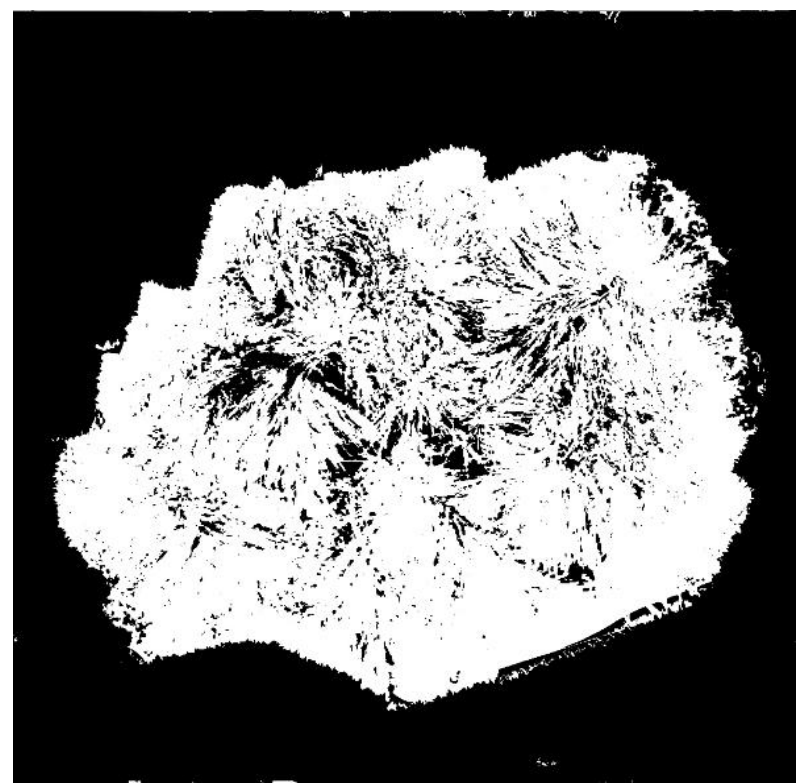

Figure 9: Image of Fig 8 after being run through Canopeo software

\section{Monitoring Protocol/Future Tasks}

As my contracted involvement in this project ended on the November 1, 2021, I will not be able to lead or guide the data collection or monitoring of the plots in the five years that are planned for this study. To ensure that my background research and knowledge on this project are not lost, I have created a monitoring protocol that can be followed by those at CWS to ensure project success moving forward. 


\section{Field Activities}

- Once the plot corners and centers have been marked and GPS tagged, the corners of each subplot should be clearly marked in a way that includes the subplot number.

- At least three times a year (before image capture) someone will walk through each plot and make sure all the subplots are still clearly marked, and free of plants that threaten to grow into or over the Carex species, or other items that could interfere with imaging such as garbage or debris.

- Once a year (July) someone from CWS will record the number of individual plant deaths that have occurred within each subplot. Dead plants will be removed or notated in some way to avoid double counting. (Do not record as dead if only part of a plant seems dead)

- Soil sampling will continue and be conducted once a year in a similar of more thorough manner that was outlined earlier.

- Soil moisture will be collected.

- If additional covariates such as microbial data are available for collection, that should also be pursued.

\section{$\underline{\text { Image Collection }}$}

- Three times a year (once in April, July, and October), for five years (starting in October of 2022, and ending in October 2027) the Thomas Dairy site will be flown by the CWS drone team to capture digital images of each of the 78 subplots created for this project.

- The subplots containing C. obnupta will be photographed and analyzed in all three seasons. The subplots containing the other two species will be photographed in all three seasons; however, as they are both deciduous, the images captured in summer may be the only useful ones for the percent cover analysis. 
- To capture these images, the GPS coordinates of the center of each subplot will be entered into the DJI Ground Station Pro flight software, which will allow the drone to fly autonomously, capturing images of each subplot.

- Each image will be captured at a height of $25 \mathrm{feet}$, with the gimbal positioned at 90 degrees.

- A drone equivalent or better in quality to the DJI Matrice 210 (M210) will be utilized unless otherwise stated by a project lead or drone flight expert.

\section{Image Handing}

- Images will be captured with a sensor equivalent or better than an X4S sensor to capture RGB data. Note: If better technology develops and/or becomes available for use by CWS during the monitoring period of this project, it may be used alongside the RGB images.

- All images must be tagged appropriately to clearly link them to the correct subplot and stored in a secure computer and back-up system.

- Before images are processed through Canopeo, the app must be calibrated to each species of Carex. To do this, three images of each species (nine images total) must be captured, hand counted by someone overlaying a 10x10 grid and calculating percent coverage of each image, lastly running the images through Canopeo, and adjusting until the result in the app closely matches the result by hand counting. For each species, the three images and their calibration numbers will be averaged out. For example, if for $C$. stipata the three images needed the calibrations of 1.03, 1.04, and 1.05, you would use a calibration level of 1.04 for all subplot images of $C$. stipata.

- Once images have been captured, they must be prepared for the Canopeo App. Each subplot image must first be cropped to only include the subplot boundaries. Second, using the Smart Lasso tool in macOS Preview, or something comparable, the area of the subplot not including the specific Carex species must be blacked out. Before running the image through Canopeo, make sure to adjust the image to the determined calibration. 
Now, run the image through the app. In a spreadsheet, record the percent coverage for the specific subplot and the date when the image was captured. Execute this for all images.

\section{$\underline{\text { Data Analysis }}$}

- The mean percent cover for each of the six subplot types will be calculated and graphed at each of the capturing times (where applicable).

- Once all data have been collected, a standard two sample t-test calculation will be utilized to determine if there is a significant difference in the growth of percent coverage of each size of each species (three t-test calculations total). A more generalized finding for growth of herbaceous species can be determined by averaging out all the growth of all plug plots compared to the average of all container plots. This will result in an analysis that can be more broadly attributed to Carex species. Note: The t-test can be run at any time during the project (i.e., at the three-year mark of growth), to test for if there is a specific point where the change in growth between the two sizes becomes significant. This can be done retroactively.

\section{Cost Analysis}

- Collect all invoices related to this project through the five years relating to the materials, and cost of planting the plots.

- Compare the costs of materials and labor between the plugs, and the containerized plots.

- Once the study has concluded, calculate the cost per square foot of cover between plugs, and containerized plants for each species.

- Track the costs related to reducing plastic waste required to propagate the plants. 


\section{Use of this Project}

The primary goal that we want to reach is in finding out what method of planting is more successful. While we hypothesize that the mature plants have lower mortality and higher percent cover by the end of the project (five years), a statistically significant answer, either way, would be helpful. Even if our hypothesis were incorrect, that would be evidence that currently, CWS and other agencies across the US are using best practices when replanting wetlands with the specific species evaluated as part of this study. If we do end up being correct in our hypothesis, and the mature plants are more successful, this would be important information to share with other wetland restoration managers in at least the PNW, probably even nationally. Once the study has concluded, I believe that the findings would be important enough to publish. Overall, I want this project to have a positive impact on the success, and ease of wetland restoration projects so that time and resources can be better spent, and more wetlands can become properly and sustainably restored.

\section{Limitations}

Working on a project over 2020-2021 created many limitations. First, because of state and federal mandates and health warnings associated with the COVID-19 pandemic, many aspects of this project had to be completed either entirely or mostly in a remote way and without inperson support. While I am proud of what I have accomplished on this project, CWS and I would have probably been able to complete more steps in the process before the end of my contract, if the multiple limitations had not transpired. This can be highlighted most prominently with the fact that because of labor shortages, supply change issues (exacerbated or caused by the pandemic), along with the record-breaking heatwave, we were unable to secure enough plants to conduct the planting of the plots during the fall of 2021, which was initially part of the plan. 


\section{Citations:}

Bullock, A., \& Acreman, M. (2003). The role of wetlands in the hydrological cycle. Hydrology and Earth System Sciences, 7(3), 358-389.

Burgin, S. (2010). 'Mitigation banks' for wetland conservation: a major success or an unmitigated disaster?. Wetlands Ecology and Management, 18(1), 49-55.

Carex unilateralis. One-sided Sedge - Carex unilateralis - Wholesale. (2021). Retrieve September 29, 2021, from http://www.heritageseedlings.com/page_185_53/carexunilateralis.

Chayka, K. (2021). Carex stipata (awl-fruited sedge). Minnesota Wildflowers. Retrieved September 29, 2021, from https://www.minnesotawildflowers.info/grass-sedge-rush/awl-fruited-sedge.

Clark, D. L., \& Wilson, M. V. (2001). Fire, mowing, and hand-removal of woody species in restoring a native wetland prairie in the Willamette Valley of Oregon. Wetlands, 21(1), 135-144.

Clean Water Services. (2021). About Us. Clean Water Services. Retrieved October 1, 2021, from https://www.cleanwaterservices.org/about-us/.

Cole, C. A. (2002). The assessment of herbaceous plant cover in wetlands as an indicator of function. Ecological Indicators, 2(3), 287-293.

Colloff, M. J., Lavorel, S., Wise, R. M., Dunlop, M., Overton, I. C., \& Williams, K. J. (2016). Adaptation services of floodplains and wetlands under transformational climate change. Ecological Applications, 26(4), 1003-1017.

Cook, R. E. (1979). Patterns of juvenile mortality and recruitment in plants. In Topics in plant population biology (pp. 207-231). Palgrave, London.

Cowardin, L. M. (2013). Classification of wetlands and deepwater habitats of the United States. Wetlands Subcommittee, Federal Geographic Data Committee.

Cronk, J. K., \& Fennessy, M. S. (2016). Wetland plants: biology and ecology. CRC press.

Davis, Hibbits, \& McCaig. September 2002. Healthy Stream Plan: Public Values. Unpublished report for Clean Water Services. 41pp.

Dummer, J. (2021). Treatment System. Fernhill. Retrieved October 26, 2021, from 
https://fernhillnts.org/watertreatment.

Durand, N., Monger, H. C., Canti, M. G., \& Verrecchia, E. P. (2018). Calcium carbonate features. In Interpretation of micromorphological features of soils and regoliths (pp. 205-258). Elsevier.

Elteto, E., Lawrence, R., \& Kinnear, J. (2021, February 24). Age and Mortality of Carex Species. personal.

Fennessy, M. S., Gernes, M., Mack, J., \& Wardrop, D. H. (2002). Using vegetation to assess environmental conditions in wetlands. Methods for evaluating wetland condition. US EPA Office of Water, Washington, 46.

Graham, R., Brill, R., Bambach, R., Hosking, J., \& Graham, N. (2019). Canopeo, a new mobile device application with potential to measure seed colour change in canola. In Agronomy Australia Conference.

Graham, S. H., Zhu, X., Kelly, H., \& Stewart, S. D. (2019). The use of Canopeo for seedling cotton health ratings in small plot research. Journal of Cotton Science, 23(3), 231-238.

Guillozet, P., Smith, K., \& Guillozet, K. (2014). The rapid riparian revegetation approach. Ecological Restoration, 32(2), 113-124.

Hammer, D. A. (1992). Creating freshwater wetlands. Lewis Publishers. Inc., Michigan.

Hough-Snee, N. W. (2010). The Effects of Flooding Depth, Fertilization, and Initial Seedling Size on the Growth and Biomass Allocation of Two Wetland Sedges, Carex Obnupta and Carex Stipata (Doctoral dissertation, University of Washington).

Kadlec, R. H. (2006). Water temperature and evapotranspiration in surface flow wetlands in hot arid climate. Ecological Engineering, 26(4), 328-340.

Keyport, S., Carson, B. D., Johnson, O., Lawrence, B. A., Lishawa, S. C., Tuchman, N. C., \& Kelly, J. J. (2019). Effects of experimental harvesting of an invasive hybrid cattail on wetland structure and function. Restoration ecology, 27(2), 389-398.

Lodge, G. M., Taylor, J. A., \& Whalley, R. D. B. (1981). Techniques for estimating plant basal area and assessing the herbage mass of some native perennial grasses. The Rangeland Journal, 3(1), 83-91.

Magee, T. K., \& Kentula, M. E. (2005). Response of wetland plant species to hydrologic 
conditions. Wetlands Ecology and Management, 13(2), 163-181.

Oregon Department of Environmental Quality. (2021). Water quality programs. State of Oregon: Water Quality Programs - Biosolids Program. Retrieved October 21, 2021, from https://www.oregon.gov/deq/wq/programs/Pages/Biosolids.aspx.

Oregon secretary of State. Oregon Secretary of State Administrative Rules. (2015). Retrieved October 20, 2021, from https://secure.sos.state.or.us/oard/displayDivisionRules.action?selectedDivision=1456.

Patrignani, A., \& Ochsner, T. E. (2015). Canopeo: A powerful new tool for measuring fractional green canopy cover. Agronomy Journal, 107(6), 2312-2320.

Pauliukonis, N., \& Gough, L. (2004). Effects of the loss of clonal integration on four sedges that differ in ramet aggregation. Plant Ecology, 173(1), 1-15.

Permit Program under CWA Section 404 | Section 404 of the Clean Water Act: Permitting Discharges of Dredge or Fill Material | US EPA. (2018). Retrieved June 2, 2019, from https://www.epa.gov/cwa-404/permit-program-under-cwa-section-404

Peterson, J. M. (1999). Soils-Part 2: Physical Properties of Soil and Soil Water.

Peverly, J. H. (1982). Stream Transport of Nutrients Through a Wetland 1. Journal of Environmental Quality, 11(1), 38-43.

Ren, M. X., \& Zhang, Q. G. (2009). The relative generality of plant invasion mechanisms and predicting future invasive plants. Weed Research, 49(5), 449-460.

Shepherd, M. J., Lindsey, L. E., \& Lindsey, A. J. (2018). Soybean canopy cover measured with Canopeo compared with light interception. Agricultural \& environmental letters, 3(1), 180031.

Smith, R. D., Ammann, A., Bartoldus, C., \& Brinson, M. M. (1995). An approach for assessing wetland functions using hydrogeomorphic classification, reference wetlands, and functional indices. ARMY ENGINEER WATERWAYS EXPERIMENT STATION VICKSBURG MS.

Smith, K., \& Ory, J. (2005). Healthy Streams Plan. Clean Water Services.

Soil Survey Staff, Natural Resources Conservation Service, United States Department of Agriculture. Web Soil Survey. Available online. Accessed [10/07/2021]. 
Sturdevant, D. (2006, April 16). Temperature Water Quality Standard Implementation - A DEQ Internal Management Directive. Oregon Department of Environmental Quality.

Thomas dairy. Tree for All. (n.d.). Retrieved October 6, 2021, from https://www.jointreeforall.org/thomas-dairy.

USDA. (2021). Carex obnupta L.H. Bailey slough sedge. USDA plants database. Retrieved September 29, 2021, from https://plants.usda.gov/home/plantProfile?symbol=CAOB3.

US Fish and Wildlife Service. (2010). Recovery plan for the prairie species of western Oregon and southwestern Washington. US Fish and Wildlife Service, Portland, Oregon. xi.

Van Der Valk, A. G., Bremholm, T. L., \& Gordon, E. (1999). The restoration of sedge meadows: seed viability, seed germination requirements, and seedling growth of Carex species. Wetlands, 19(4), 756-764.

Wilson, B.L., R. Brainerd, D. Lytjen, B. Newhouse, and N. Otting (2008). Field Guide to the Sedges of the Pacific Northwest. Oregon State University Press, Corvallis, OR.

Wilson, R. F., \& Mitsch, W. J. (1996). Functional assessment of five wetlands constructed to mitigate wetland loss in Ohio, USA. Wetlands, 16(4), 436-451.

Yadav, V. K., Yadav, K. K., Cabral-Pinto, M., Choudhary, N., Gnanamoorthy, G., Tirth, V., ... \& Khan, N. A. (2021). The processing of calcium rich agricultural and industrial waste for recovery of calcium carbonate and calcium oxide and their application for environmental cleanup: a review. Applied Sciences, 11(9), 4212.

Zotz, G., Hietz, P., \& Schmidt, G. (2001). Small plants, large plants: the importance of plant size for the physiological ecology of vascular epiphytes. Journal of Experimental Botany, 52(363), 2051-2056. 


\section{Appendix A:}

Below are the results from the soil samples taken at Thomas Dairy on July $29^{\text {th }}, 2021$. C.E.C is a measure of how many cations can be retained on soil particle surfaces. Sulfur (S), zinc (Zn), manganese $(\mathrm{Mn})$, iron (Fe), copper $(\mathrm{Cu})$, and boron $(\mathrm{B})$ are all measured in parts per million (ppm),

\begin{tabular}{|c|c|c|c|c|c|c|c|c|c|}
\hline Name & Depth (in) & Organic matter \% (rate) & P1 ppm & P2 ppm & K ppm & Mg ppm & Ca ppm & \multicolumn{2}{|c|}{ Na ppm pH } \\
\hline $5 A$ & $0-12$ & 2.8 & 15 & 25 & 62 & 387 & 1566 & 50 & 5.8 \\
\hline $5 C$ & $12-24$ & 1.6 & 5 & 6 & 98 & 917 & 2379 & 121 & 6.2 \\
\hline $6 \mathrm{~A}$ & $0-12$ & 3.5 & 21 & 37 & 84 & 371 & 1766 & 76 & 5.4 \\
\hline $6 \mathrm{C}$ & $12-24$ & 1.5 & 12 & 15 & 126 & 952 & 2624 & 175 & 5.9 \\
\hline $8 \mathrm{~A}$ & $0-12$ & 3.4 & 27 & 53 & 132 & 341 & 1856 & 40 & 5.8 \\
\hline $8 C$ & $12-24$ & 1.7 & 9 & 21 & 81 & 316 & 1471 & 45 & 6 \\
\hline $9 A$ & $0-12$ & 3.7 & 20 & 36 & 75 & 460 & 1787 & 61 & 6.1 \\
\hline $9 C$ & $12-24$ & 1.5 & 7 & 23 & 91 & 999 & 2427 & 157 & 6.7 \\
\hline $10 A$ & $0-12$ & 3 & 14 & 30 & 136 & 286 & 1622 & 29 & 5.5 \\
\hline $10 \mathrm{C}$ & $12-24$ & 1.7 & 11 & 22 & 97 & 307 & 1590 & 44 & 5.8 \\
\hline $11 \mathrm{~A}$ & $0-12$ & 3.5 & 23 & 59 & 98 & 335 & 1980 & 47 & 5.6 \\
\hline $11 \mathrm{C}$ & $12-24$ & 2.5 & 29 & 52 & 67 & 365 & 2131 & 33 & 5.8 \\
\hline $12 \mathrm{~A}$ & $0-12$ & 3.5 & 17 & 34 & 113 & 922 & 2621 & 148 & 5.9 \\
\hline $12 \mathrm{C}$ & $12-24$ & 1.8 & 8 & 23 & 120 & 1188 & 2819 & 154 & 6.6 \\
\hline $13 \mathrm{~A}$ & $0-12$ & 2.9 & 14 & 31 & 53 & 314 & 1339 & 68 & 5.6 \\
\hline $13 C$ & $12-24$ & 1.3 & 3 & 5 & 86 & 768 & 1851 & 130 & 6.3 \\
\hline $15 \mathrm{~A}$ & $0-12$ & 3.5 & 30 & 55 & 78 & 272 & 1744 & 31 & 5.6 \\
\hline $15 \mathrm{C}$ & $12-24$ & 1.6 & 25 & 54 & 61 & 262 & 1580 & 34 & 5.7 \\
\hline $16 \mathrm{~A}$ & $0-12$ & 3 & 33 & 60 & 164 & 199 & 1689 & 25 & 5.5 \\
\hline $16 \mathrm{C}$ & $12-24$ & 2 & 23 & 41 & 151 & 185 & 1680 & 23 & 5.7 \\
\hline
\end{tabular}




\begin{tabular}{cccccccccc}
\hline Buffer index C.E.C (meq/100g) & \% K & \% Mg & \% Ca & \% H & \% Na & Nitrate-N ppm & Nitrate-N Ibs/A S \\
\hline 6.7 & 14.1 & 1.1 & 22.9 & 55.5 & 29 & 1.5 & 1 & 4 & 13 \\
6.6 & 23.1 & 1.1 & 33.1 & 51.5 & 12 & 2.3 & 2 & 7 & 10 \\
6.5 & 17.5 & 1.2 & 17.7 & 50.5 & 28.7 & 1.9 & 2 & 7 & 33 \\
6.5 & 26.6 & 1.2 & 29.8 & 49.3 & 16.8 & 2.9 & 1 & 4 & 17 \\
6.6 & 15.6 & 2.2 & 18.2 & 59.5 & 19 & 1.1 & 1 & 4 & 26 \\
6.7 & 12.2 & 1.7 & 21.6 & 60.3 & 14.8 & 1.6 & 1 & 4 & 10 \\
6.7 & 15.4 & 1.2 & 24.9 & 58 & 14.2 & 1.7 & 1 & 4 & 12 \\
\hline & 21.4 & 1.1 & 38.9 & 56.8 & 0 & 3.2 & 1 & 4 & 10 \\
6.6 & 14.9 & 2.3 & 16 & 54.4 & 26.5 & 0.8 & 2 & 7 & 21 \\
6.7 & 13.5 & 1.8 & 19 & 58.9 & 18.9 & 1.4 & 2 & 7 & 16 \\
6.6 & 17.1 & 1.5 & 16.3 & 57.9 & 23.1 & 1.2 & 1 & 4 & 20 \\
6.6 & 17.3 & 1 & 17.6 & 61.6 & 19 & 0.8 & 1 & 4 & 12 \\
6.5 & 26.1 & 1.1 & 29.4 & 50.2 & 16.8 & 2.5 & 1 & 4 & 23 \\
6.8 & 26.6 & 1.2 & 37.2 & 53 & 6.1 & 2.5 & 1 & 4 & 16 \\
6.6 & 12.7 & 1.1 & 20.6 & 52.7 & 23.3 & 2.3 & 2 & 7 & 21 \\
6.7 & 18.3 & 1.2 & 35 & 50.6 & 10.1 & 3.1 & 2 & 7 & 9 \\
6.6 & 14.8 & 1.4 & 15.3 & 58.9 & 23.5 & 0.9 & 2 & 7 & 17 \\
6.6 & 13.2 & 1.2 & 16.5 & 59.8 & 21.4 & 1.1 & 2 & 7 & 12 \\
6.6 & 14.3 & 2.9 & 11.6 & 59.1 & 25.6 & 0.8 & 2 & 7 & 32 \\
6.6 & 13.2 & 2.9 & 11.7 & 63.6 & 21 & 0.8 & 2 & 7 & 15 \\
\hline
\end{tabular}




\begin{tabular}{ccccccc}
\hline Zn & Mn & Fe & Cu & B & Excess lime rate & Soluble Salts (mmhos/cm) \\
\hline 2 & 19 & 114 & 1.5 & 0 & $\mathrm{~L}$ & 0.2 \\
0 & 6 & 34 & 0.6 & 0 & $\mathrm{~L}$ & 0.2 \\
2 & 32 & 162 & 1.8 & 0 & $\mathrm{~L}$ & 0.2 \\
1 & 11 & 31 & 0.4 & 1 & $\mathrm{~L}$ & 0.3 \\
3 & 14 & 165 & 1.8 & 0 & $\mathrm{~L}$ & 0.2 \\
1 & 8 & 82 & 0.6 & 0 & $\mathrm{~L}$ & 0.2 \\
2 & 12 & 123 & 1.5 & 0 & $\mathrm{~L}$ & 0.2 \\
1 & 4 & 39 & 0.7 & 0 & $\mathrm{~L}$ & 0.2 \\
1 & 12 & 150 & 0.9 & 0 & $\mathrm{~L}$ & 0.2 \\
1 & 16 & 98 & 0.9 & 0 & $\mathrm{~L}$ & 0.2 \\
3 & 14 & 143 & 1.4 & 0 & $\mathrm{~L}$ & 0.2 \\
2 & 12 & 105 & 1.2 & 0 & $\mathrm{~L}$ & 0.2 \\
2 & 21 & 91 & 1 & 0 & $\mathrm{~L}$ & 0.3 \\
1 & 6 & 32 & 0.6 & 0 & $\mathrm{~L}$ & 0.2 \\
1 & 20 & 125 & 1.1 & 0 & $\mathrm{~L}$ & 0.2 \\
1 & 12 & 69 & 0.7 & 0 & $\mathrm{~L}$ & 0.2 \\
2 & 15 & 125 & 1.2 & 0 & $\mathrm{~L}$ & 0.2 \\
1 & 11 & 100 & 1 & 0 & $\mathrm{~L}$ & 0.2 \\
2 & 27 & 121 & 1.5 & 0 & $\mathrm{~L}$ & 0.2 \\
1 & 11 & 79 & 0.9 & 0 & $\mathrm{~L}$ & 0.2 \\
\hline
\end{tabular}




\section{Appendix B:}

Below is a map of the placement of the irrigation lines at the Thomas Dairy site.

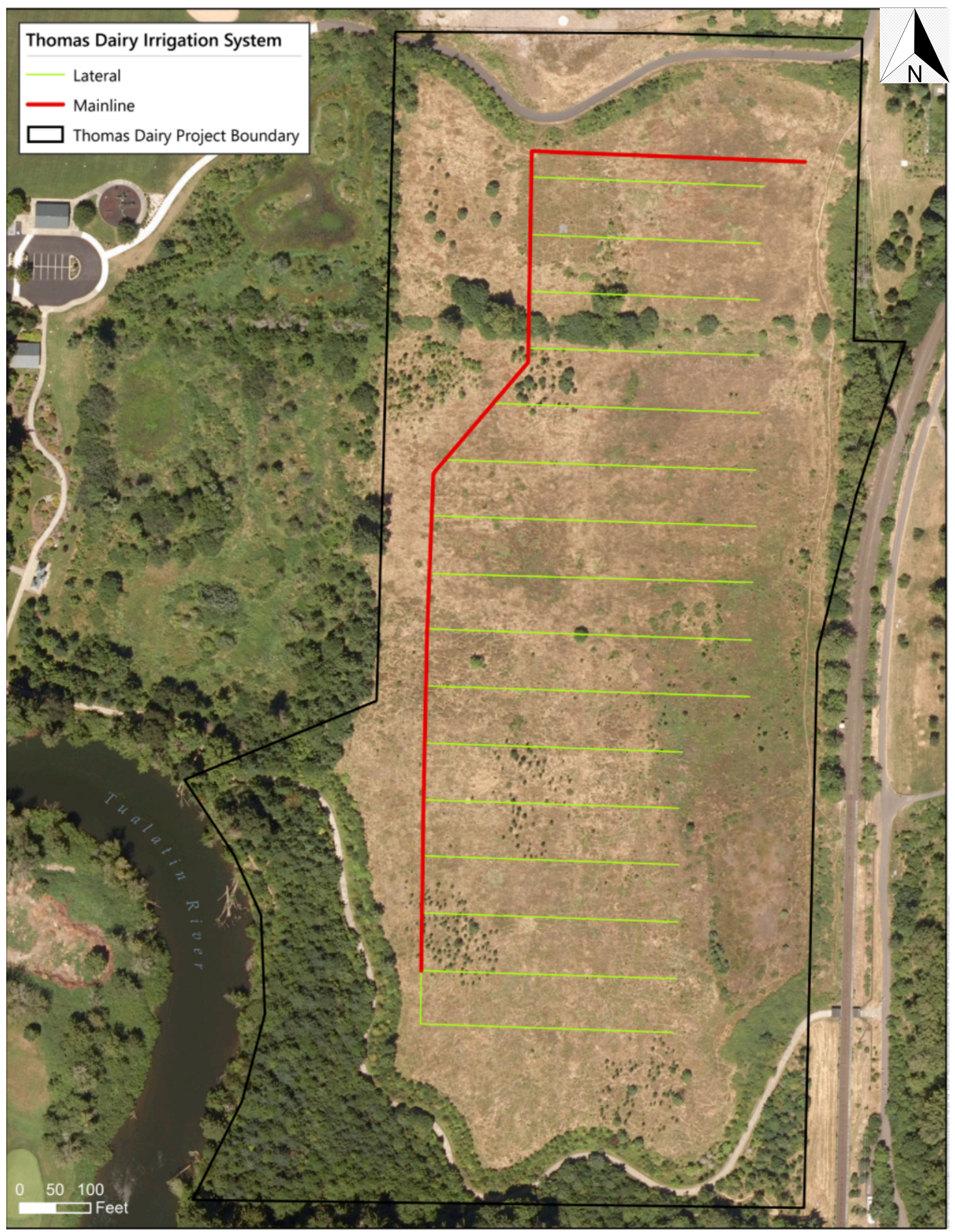




\section{Appendix C:}

Below is the script for the power analysis (using power.t.test) I completed to figure out the number of plots needed for C. obnupta.

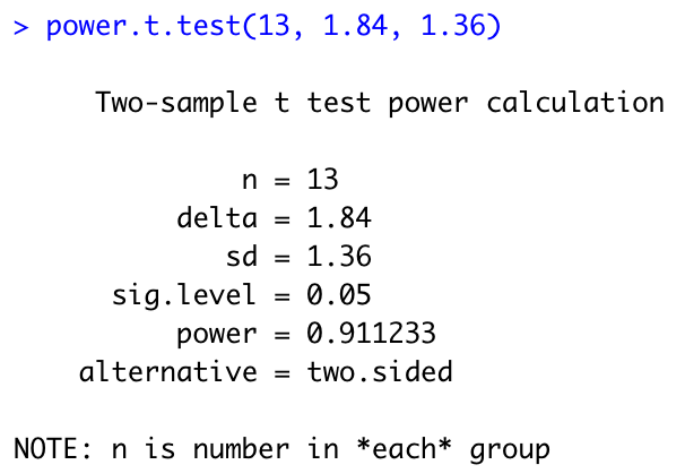

Below is the script for the power.t.test I completed to figure out the number of plots needed for C. stipata

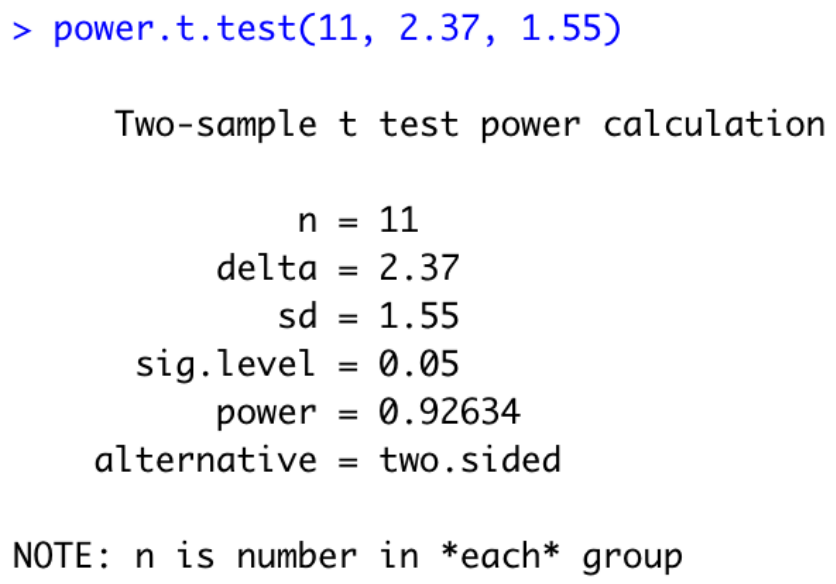

Below is the script for the power.t.test I completed to figure out the number of plots needed for $C$. unilateralis

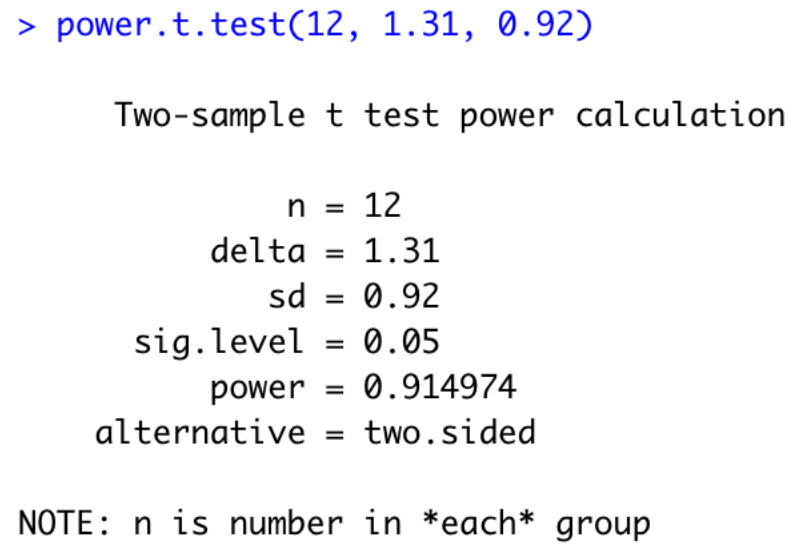

